\title{
WestVirginiaUniversity
}

THE RESEARCH REPOSITORY @ WVU

Graduate Theses, Dissertations, and Problem Reports

2017

\section{Characterizing Risk Factors of Adolescent Electronic Cigarette}

Use

Paul T. Enlow

Follow this and additional works at: https://researchrepository.wvu.edu/etd

\section{Recommended Citation}

Enlow, Paul T., "Characterizing Risk Factors of Adolescent Electronic Cigarette Use" (2017). Graduate Theses, Dissertations, and Problem Reports. 5545.

https://researchrepository.wvu.edu/etd/5545

This Dissertation is protected by copyright and/or related rights. It has been brought to you by the The Research Repository @ WVU with permission from the rights-holder(s). You are free to use this Dissertation in any way that is permitted by the copyright and related rights legislation that applies to your use. For other uses you must obtain permission from the rights-holder(s) directly, unless additional rights are indicated by a Creative Commons license in the record and/ or on the work itself. This Dissertation has been accepted for inclusion in WVU Graduate Theses, Dissertations, and Problem Reports collection by an authorized administrator of The Research Repository @ WVU.

For more information, please contact researchrepository@mail.wvu.edu. 
Characterizing Risk Factors of Adolescent Electronic Cigarette Use

Paul T Enlow, M.S.

Dissertation submitted to The Eberly College of Arts and Sciences

at West Virginia University

in partial fulfillment of the requirements for the degree of

Doctor of Philosophy in

Psychology

Christina L. Duncan, Ph.D., Chair

Melissa Blank, Ph.D.

Geri Dino, Ph.D.

Amy Herschell, Ph.D.

Nicholas Turiano, Ph.D.

Department of Psychology

Morgantown, West Virginia

2017

Keywords: Adolescent, Electronic Cigarette, Substance Use, Psychology

Copyright 2017: Paul T. Enlow 


\section{ABSTRACT \\ Characterizing Risk Factors of Adolescent Electronic Cigarette Use}

\section{Paul T. Enlow}

Use of electronic cigarettes (e-cigs, electronic vapor products) rose dramatically in the United States over the past decade and a half, most notably among high school students. This increase in use, coupled with concerns about renormalization of smoking and potential health risks, has raised concern that e-cigs represent a growing public health risk. Unfortunately, there is limited research on risk factors for e-cig use among teens, and many studies have methodological flaws that are unaddressed. The primary aim of the current study is to apply an empirically tested theory of health-risk behaviors in adolescents, Problem Behavior Theory (PBT), to lifetime- and current-use of electronic cigarettes. The second aim was to identify individual risk factors for different levels of e-cig use. A total of 519 high school students between the age of 13 and 19 years $(\mathrm{M}$ age $=15.99 ; 57.9 \%$ female $)$ were recruited from four schools and one adolescent medicine clinic. Students completed a packet of questionnaires during their regularly scheduled classes or while attending a clinic appointment. Structural Equation Modeling and logistic regressions were used to test the primary and secondary aims, respectively. Results partially supported the hypotheses of the first aim. The PBT structural model demonstrated good fit, but not all 5 domains were associated with e-cig use. The Biology/Genetics, Perceived Environment, Personality, and Behavior latent variables were significant predictors of lifetime e-cig use. The Personality and Behavior latent variables predicted current e-cig use; The Social Environment construct was not associated with either outcome variable. Results from binomial and multinomial logistic regressions identified risk- (cigarette, alcohol, and marijuana use; modeling of smoking; and extraversion) and protective- (self-efficacy to resist using e-cigs, perceived costs of using e-cigs) factors of lifetime-only e-cig use. Results from logistic regressions also identified risk (marijuana use, modeling of smoking) and protective factors (perceived costs, smoking self-efficacy) for past-30-day e-cig use relative to lifetime-only use. Overall, results suggest that personality and behavioral variables were the strongest predictors of e-cig use. These results can be used to inform substance use screening and help develop educational prevention efforts. 


\section{ACKNOWLEDGEMENTS}

I would like to thank my advisor and committee chair, Christina Duncan, for her enduring support and guidance throughout this project and my graduate training. I am forever grateful for your encouragement to take on challenging and exciting opportunities, push myself in all areas of my training, and help fostering a desire to continue learning and growing.

A special thank you to the current and former members of the Pediatric Psychology lab at West Virginia University. Desireé Williford, Ellen Manegold, and Kristine Durkin, I could not have completed this project without your help recruiting participants and entering enough data to last a lifetime.

I am grateful for my committee members, Melissa Blank, Amy Herschell, Nicholas Turiano, and Geri Dino, and all their valuable feedback through the development and implementation of this project. Thank you to the Tobacco Research Group in the WV Prevention Research Center for their assistance with this study. I would also like to say thank you to administrators and teachers who helped make this study possible, and to all of the students who participated in this project.

Finally, I would like to thank my family and friends for their continuous encouragement and guidance throughout my graduate training. A very special thank you to my office-mates and close friends, Trisha Hopkins, Valerie Blake, and Lauren Quetsch, for their support in and out of the office. 


\section{TABLE OF CONTENTS}

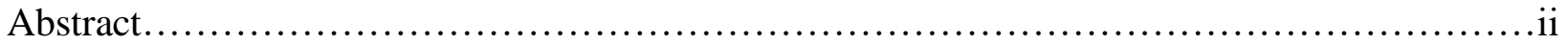

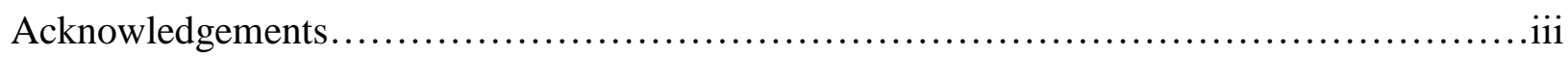

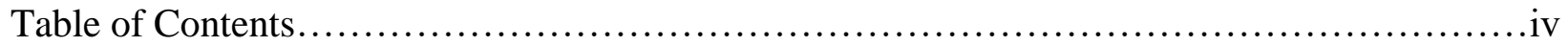

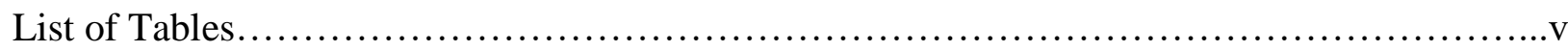

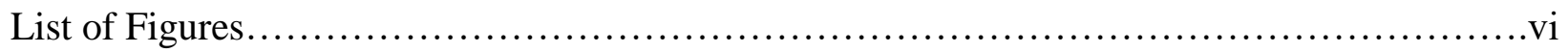

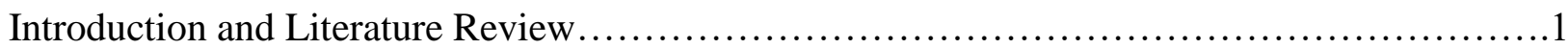

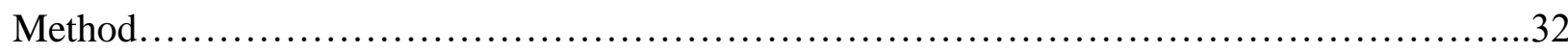

Participants............................................................ 32

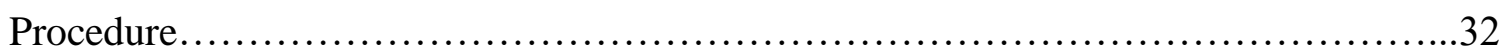

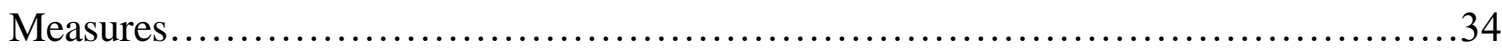

Results................................................................... 42

Preliminary Analyses...................................................42

Aim 1 Analyses..........................................................47

Aim 2 Analyses......................................................... 51

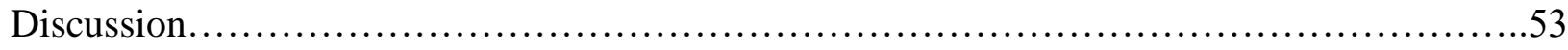

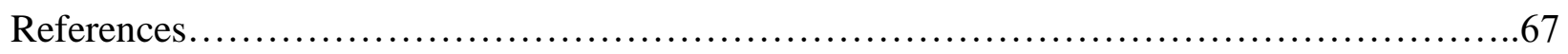

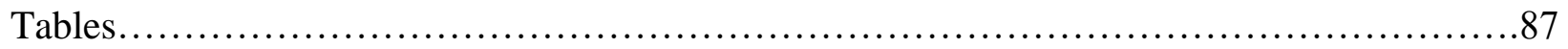

Figures.................................................................. 95 


\section{List of Tables}

Coding of Predictor Variables Used in Analyses......................................... 87

Participant Demographics....................................................... 88

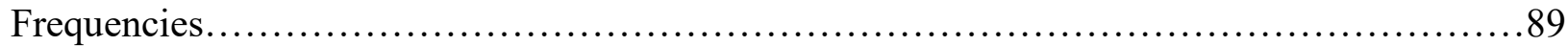

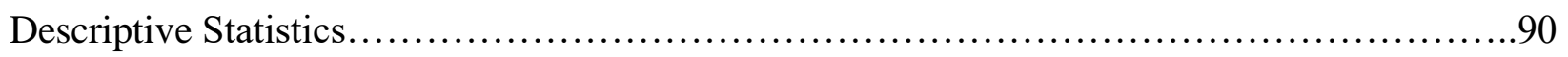

Binomial Logistic Regression Classification Table......................................91

Binomial Logistic Regression Predicting Lifetime Electronic Cigarette Use.................92

Multinomial Logistic Regression Classifying Level of E-Cig Use........................93

Multinomial Logistic Regression Predicting Levels of E-Cig Use..........................94 


\section{List of Figures}

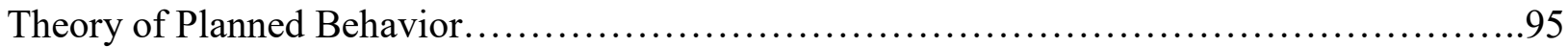

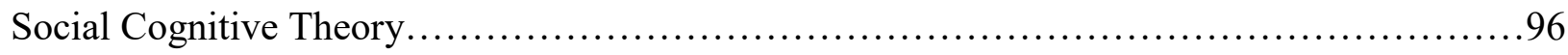

Conceptual Framework for Problem Behavior Theory .....................................99

First Iteration of Measurement Model............................................................ 98

Second Iteration of Measurement Model.................................................... 99

Third and Final Iteration of Measurement Model............................................100

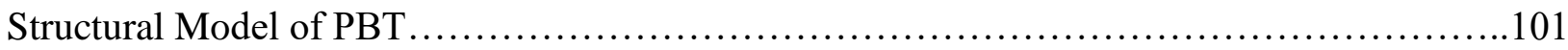




\section{Characterizing Risk Factors of Adolescent Electronic Cigarette Use}

Smoking is one of the leading preventable causes of death in the United States (WHO,

2011). Because of this, countless cessation and prevention programs have been created, disseminated, and proven effective. Adolescents are one population that has received a substantial amount of attention; early intervention can prevent teens from becoming life-long smokers and thereby mitigate negative effects on health (CDC, 1994). Between 1991 and 2009, the number of adolescents who reported currently smoking cigarettes fell by approximately $30 \%$, and the number of youth who ever tried cigarettes was cut in half (CDC, 2010). However, a new product, electronic cigarettes (e-cigs, vapor products), has the potential to undo decades' worth of progress by renormalizing smoking, facilitating adolescent substance use, and potentially acting as a gateway to regular tobacco use (Bell \& Keane, 2012; CDC, 2013; Duke et al., 2014; Durmowicz, 2014; Fairchild, Bayer, \& Colgrove, 2014; Peters, Meshack, Lin, Hill, \& Abughosh, 2013; Wills et al., 2016)

Use of electronic cigarettes, also referred to as "vaping," began in the early to mid-2000's after the devices were introduced by a Chinese manufacturer, RUYAN (Bell \& Keane, 2012). Since their introduction, e-cigs have changed substantially. However, all designs share three basic components: (1) a battery, (2) a cartridge or tank that contains the e-liquid, and (3) a heating element, also known as an atomizer (Farsalinos et al., 2014). To use an electronic cigarette, the user (sometimes referred to as a "vaper") inhales or presses a button (depending on the type of device), which activates the heating element, vaporizes the liquid, and produces vapor that is then inhaled (Brown \& Cheng, 2014; Orellana-Barrios, Payne, Mulkey, \& Nugent, 2015).

Since 2003, there have been three "generations" of electronic cigarettes (Bhatnagar et al., 2014; Grana, Benowitz, \& Glantz, 2014). The first generation of vapor products, commonly 
known as "cigalikes," look like conventional cigarettes (Brown \& Cheng, 2014). These devices can be single use (i.e., disposable) or reusable. Second generation products are larger (i.e., the size of a pen) and do not resemble cigarettes (Bhatnagar et al., 2014; Grana et al., 2014). These devices have longer-lasting batteries and larger tanks that hold more e-liquid. Many secondgeneration products facilitated the personalization of the vaping experience through different types of batteries (e.g., longer lasting, higher wattage) and liquids (e.g., different flavors and nicotine concentrations). Finally, third generation devices represent the newest iteration of vapor products that allow intensive customization by users (Bhatnagar et al., 2014; Brown \& Cheng, 2014). Specifically, vapers can incorporate a variety of batteries, wicks, and atomizers in addition to different types of e-liquids.

Over the past decade, electronic cigarettes became widely available in the United States. They are often marketed as tobacco cessation tools and healthier alternatives to conventional cigarettes (Bhatnagar et al., 2014; Grana \& Ling, 2014; Yamin, Bitton, \& Bates, 2010). Moreover, loopholes in regulations as well as novel approaches to advertising (e.g., social media, websites, and internet forums) expose a substantial proportion of the population to the messages that vapor products are a healthy alternative to cigarettes (Bhatnagar et al., 2014; Duke et al., 2014; Grana \& Ling, 2014; Yamin et al., 2010). However, recent reviews on the health effects of electronic cigarettes have raised questions about these claims made by electronic cigarette companies.

\section{Health Risks of Electronic Cigarettes}

E-liquids. Many questions about the safety of electronic cigarettes focus on the liquid, commonly referred to as e-liquid, e-juice, or juice, which is vaporized and inhaled. E-liquids contain a variety of ingredients such as water, nicotine, and flavorings/additives that are mixed 
within a solvent (Kosmider et al., 2014). The two most common solvents are vegetable glycerin (e.g., vegetable oil, VG) and propylene glycol (PG). Although both glycerin and PG are considered to be relatively harmless for most people (National Institutes of Health, 2010; 2012), there is a concern that the temperature at which e-juices are heated is high enough to alter their physical properties and form toxic substances (Paschke, Scherer, \& Heller, 2002). Indeed, investigators repeatedly found that vaporization of e-juices produces carcinogens, such as formaldehyde and acetaldehyde (Goniewicz et al., 2014; Kosmider et al., 2014; McAuley et al. 2012). Similarly, the United States Food and Drug Administration (FDA) found trace amounts of diethylene glycol in e-liquids, which is a potentially toxic solvent when ingested orally (Westenberger, 2009). A number of studies also found tobacco-specific nitrosamines (carcinogenic compounds) in e-liquids and the resulting vapor (Goniewicz et al., 2014; Kim \& Shin, 2013; Westenberger, 2009). Moreover, research findings suggest that flavored e-juices may be toxic to embryonic and stem cells (Bahl et al., 2012), although these findings have not been consistent (Romagna et al., 2013) and the cytotoxicity is lower when compared with regular cigarettes (Cervellati et al., 2014). Similarly, while potentially harmful compounds were observed in e-juices, it should be noted that the levels are substantially lower when compared with conventional cigarettes (Goniewicz et al., 2014; Kosmider et al., 2014; McAuley et al., 2012). Overall, some harmful chemicals appear to be present in e-liquids. However, the mixed findings make it difficult to compare the levels of these toxicants with conventional cigarettes or to make definite statements regarding the safety of e-cigarettes.

Nicotine. The presence of nicotine in e-liquids also raises some health concerns, specifically for adolescents. For many people, nicotine is a relatively harmless drug that targets the cholinergic system and is associated with motor and cognitive functioning (e.g., memory, 
attention; Albuquerque, Pereira, Alkondon, \& Rogers, 2009). However, there is evidence of adverse effects from exposure to nicotine during periods of development. In a recent review, England et al. (2015) noted that, because the cholinergic system is involved in neural changes during puberty, teens who smoke may have impairments in cognitive functioning. Even more alarming is the fact that researchers reported inconsistencies between the amount of nicotine advertised on e-liquids and what was found in laboratory tests (Cameron et al., 2013; Goniewicz et al., 2013; Goniewicz et al., 2015; Westenberger, 2009). Consequently, youth may be absorbing more nicotine than they think. Finally, results from recent studies suggest that there may be a risk of second-hand exposure to nicotine as there were elevated levels of airborne nicotine following use of electronic cigarettes (Ballbé et al., 2014). Altogether, this suggests that use of electronic cigarettes during adolescence could potentially impact development and have long-lasting adverse health effects. Moreover, the discrepant findings regarding the amount of nicotine in e-liquids make it difficult to accurately estimate potential health risks associated with e-cigarette use in general.

Heavy Metals. Another concern is the presence of heavy metals in e-cig vapor. Williams and colleagues (2013) found that the amount of lead and chromium in the vapor from ecigarettes was comparable with the levels found in conventional cigarette smoke; however, the level of nickel was substantially greater than regular cigarettes. Other authors (Goniewicz et al., 2014) found metals such as lead, nickel, and cadmium in e-cigarette vapor, but at much lower levels than Williams and colleagues (2013) found. Even at lower levels, however, these metals are associated with respiratory diseases and may pose a health risk to consumers. Furthermore, one study even found evidence of increased levels of aluminum in the air after participants used 
e-cigs (Schober et al., 2014). Therefore, heavy metals in second-hand vapor also may pose a health risk.

Physiological Effects. Lastly, many investigators focused on the physiological effects of electronic cigarettes. One such health effect is an adverse event or an unexpected medical incident related to the use of a pharmaceutical product. There were reports of mild adverse events in e-cig users, such as dizziness, coughing, and throat irritation (Chen, 2013). However, the American Association of Poison Control Centers (AAPCC) reported that the number of poison control calls regarding exposure to e-liquid more than doubled between 2013 and 2014 (AAPCC, 2015); half of these calls concerned children under the age of six who reportedly came in contact with liquid nicotine and became ill. Because of the high nicotine content of e-liquids, anyone, especially youth, who swallows the liquid may be at risk for acute nicotine intoxication. Although severe poisonings with e-cigarettes are rare, the AAPCC recommends taking precautionary measures (e.g., contacting poison control hotlines) following any level of exposure to e-liquids (AAPCC, 2015).

Adverse events can be dramatic, but they do not provide realistic estimates of the everyday impact of electronic cigarettes on physical well-being. Studies of current cigarette smokers who did not have previous experience with vapor products reported increases in airway resistance (Marini et al., 2014; Vardavas et al., 2012) as well as decreases in airway conductance (Palamidas et al., 2014) after vaping. Similar effects were observed in healthy participants, as well as those with chronic obstructive pulmonary disease (COPD) and asthma (Palamidas et al., 2014). Some studies also examined how the use of electronic cigarettes impacted the fraction of exhaled nitric oxide, which is an indicator of airway inflammation and pulmonary disease (e.g., asthma, COPD). Vardavas and colleagues (2012) found immediate decreases in exhaled nitric 
oxide in adult participants after using an electronic cigarette. Although these effects have been consistent across all studies, they all measure acute impact; no studies evaluated the long-term effects of e-cigarette use on overall physical well-being. Consequently, it is not clear how prolonged use of these devices will impact health functioning across time. Because adolescents are undergoing physical and mental changes due to puberty, it is even more important to understand the potential physical and health ramifications of e-cigarette use in youth.

Summary of Health Risks for E-Cigarettes. Taken together, the results of these studies paint a complex picture regarding the health risks of electronic cigarettes. Carcinogenic and toxic chemicals were repeatedly observed in e-liquid and vapors, but the levels are sometimes lower when compared with conventional cigarettes. Although the levels of these chemicals are lower than other tobacco products, it is difficult to rule out health risks from prolonged use or synergistic effects amongst these chemicals (Pisinger \& Døssing, 2014). Short-term decreases in pulmonary functioning after using an electronic cigarette also were observed, but no studies have established if these effects are long lasting. Most concerning is the fact that it is not clear what additives and chemicals e-liquids contain given the uncontrolled nature of these devices. Pisinger and Døssing (2014) noted that the e-liquids used in many studies did not display the proportion of different chemicals and solvents contained in the solution. Additionally, the amount of nicotine advertised was frequently discrepant (i.e., higher or lower) from what was observed in laboratory studies (e.g., Goniewicz et al., 2013, 2015). This is especially alarming as it suggests that quality control of these products is low and thus unknown contaminants could be introduced and subsequently consumed. Therefore, e-cigarettes may be a viable harm reduction product for current smokers but represent a health risk for those who do not smoke. Moreover, vulnerable populations, such as adolescents, may be at greater risk for the adverse effects of vapor products. 


\section{Theories of Substance Use in Adolescents}

Adolescents who use electronic cigarettes may be at risk for adverse health outcomes because of the chemicals contained within e-liquids. To safeguard this vulnerable population, it is important to prevent experimentation with these devices. Unfortunately, research on e-cig use is relatively new; a review of the early e-cig literature by Carroll-Chapman and $\mathrm{Wu}$ (2014) found only six publications that focused on adolescents. The findings of these studies may represent only an early understanding of what factors predict youth use of electronic cigarettes. Therefore, investigators must turn to other substance use literatures to hypothesize what variables contribute to teen experimentation with vapor products. Many theoretical models were developed to highlight the important predictors of substance use. These models focus on a variety of factors, including cognitions and evaluations of the costs and benefits of substance use, modeling by peers and parents, intrapersonal factors, and combinations of a number of different possible influences.

Theory of Planned Behavior. Cognitive theories posit that beliefs regarding potential costs and benefits are the primary explanation of adolescent substance use. One of the more widely applied theories is the Theory of Planned Behavior (TPB; see Figure 1). The TPB focuses on how substance-specific attitudes, normative beliefs, and self-efficacy predict intentions, which subsequently predict substance use (Ajzen 1985; 1988). For example, this theory could be used to conceptualize healthy eating behaviors. The TPB states that an individual's intention to eat healthier foods would depend upon the perceived costs and benefits of changing their eating habits (i.e., attitude toward the behavior), whether they believe their peers will support or oppose their actions (i.e., subjective norms), and how much they feel they can control their eating habits (i.e., perceived behavioral control). People's intention to change their eating habits is higher if 
they perceive change as beneficial, supported by friends, and within their ability to change. High intentions to eat healthy then predict actual changes in eating habits. Additionally, perceived behavioral control is believed to directly influence actual behavior as well as behavioral intentions. To test its utility, investigators applied this conceptual model to a variety of health behaviors. Findings from two prospective studies suggest that the TPB predicts intentions and future use of tobacco and alcohol (Guo et al., 2007; Marcoux \& Shope, 1997). Additionally, the TPB explained a significant amount of the variance of intention and use of ecstasy, a recreational drug (Orbell, Blair, Sherlock, \& Conner 2001).

Although there is evidence to support the utility of the TPB in predicting substance use, there are some limitations to this model. First, it is possible that cognitions about substances are a consequence rather than a predictor of health behaviors (Petraitis, Flay, \& Miller, 1995). This is particularly noteworthy if studies are cross-sectional rather than longitudinal in design. However, cross-sectional studies are useful when the literature is limited (i.e., research on electronic cigarettes) and it is necessary to identify potential risk factors for a behavior prior to conducting a more intensive longitudinal study. A related weakness of the TPB is that it does not explain what leads to youths' positive or negative beliefs regarding certain health behaviors. There also is evidence to suggest that this theory may not encompass all of the variables associated with particular health-risk behaviors. A meta-analysis by McEachan, Conner, Taylor, and Lawton (2011) suggested that the utility of the TPB varied by type of health behavior. Specifically, the TPB accounted for a larger amount of variance for physical activity $(23.9 \%)$ and diet $(21.2 \%)$ than it did for health-risk behaviors (e.g., smoking, speeding, and drug use), safe sex, and abstinence from drugs (13.8-15.3\%). Because the current study aims to examine adolescents' use of electronic cigarettes, the TPB may not be ideal. Specifically, the TPB does not incorporate 
social influences of behavior, which could potentially limit its ability to predict e-cig use, as peer influence is an important variable to consider with this particular health behavior (Ramirez, Hinman, Sterling, Weisner, \& Campbell, 2012).

Social Cognitive Theory. Many researchers also considered the relevance of social learning theory, which suggests that adolescents' attitudes towards and use of substances are heavily influenced by parent and peer modeling, and subsequent imitation of these behaviors (Petraitis, Flay, \& Miller, 1995). Social Cognitive Theory (SCT; see Figure 2) is one model that highlights bidirectional influences between personal factors (e.g., attitudes and beliefs about drugs), the environment (e.g., attending parties with alcohol, observing parents smoke or drink), and actual substance use behaviors (e.g., trying a cigarette, getting drunk; Bandura, 1986). Family and friends' substance use will shape adolescents' beliefs about substance-related outcomes (e.g., social benefits, health consequences). Moreover, teens'substance-related selfefficacy will be influenced by peer and parent behavior (Bandura, 1977, 1982). Youth may feel pressured to use a substance if their friends also use it. For example, adolescents may observe their parents using alcohol and having a good time, which thereby influences their beliefs that alcohol is safe and enjoyable. Because they possess these positive attitudes, adolescents may be more willing to place themselves in situations in which alcohol is readily available (e.g., unsupervised parties). These cognitive and environmental factors increase the chance that they will be offered and consume an alcoholic drink. Desirable consequences of drinking (e.g., social acceptance, physiological effects) may also influence beliefs about alcohol, which subsequently influences the other factors (e.g., behavior, environment).

Evidence in support of SCT includes the results from two studies that found that youth were more likely to use marijuana if their friends possessed positive opinions regarding 
marijuana (Bailey \& Hubbard, 1990), or if they were offered substances (e.g., cigarettes, alcohol) by their friends (Kandel, Kessler, \& Margulies, 1978). Similarly, social learning variables in another study (e.g., modeling, perceived peer or parent norms) accounted for over half of the variance of adolescent alcohol and marijuana use (Akers et al., 1979).

Although the social component of SCT is implicated as an important predictor of substance use, there are some limitations of this theory. First, deviant peers may be a consequence rather than a predictor of adolescent substance use (Fisher \& Bauman, 1988; Simons-Morton \& Farhart, 2010). This means that instead of being influenced by peers, teens who are interested in using substances seek out friends that engage in similar behaviors. Second, SCT does not fully explain why teens associate with deviant peers (Petraitis, Flay, \& Miller, 1995). This leaves many unanswered questions, which could be important to understanding adolescent use of e-cigarettes, for example.

Intrapersonal Theories. A third group of theories emphasizes the role that intrapersonal characteristics play in predicting adolescent health-risk behaviors. The core assumption of these theories is that teens will differ in the ways they interact with substance-using peers, and these individual differences are due to personality, mood, and behaviors (Petraitis, Flay, \& Miller, 1995). For instance, a teenager may have a number of intrapersonal characteristics that can lead to or prevent substance use. He or she may be described as sensation-seeking, have poor selfesteem, and experience academic difficulties. Because of these challenges, this teen may be more likely to seek out reinforcement in non-traditional ways, such as using drugs and associating with deviant peers. Conversely, a teen with high self-esteem may not feel the need to engage in substance use. Results from a study by Kumpfer and Turner (1990) suggested that teenagers' positive attitudes towards school were negatively related to substance use, which lends credence 
to intrapersonal theories. Another study found that lower self-esteem was related to engagement with deviant peers and subsequent substance use (Kaplan et al., 1982).

However, there are many limitations to intrapersonal theories. First, individual characteristics are weak predictors of substance use. For instance, multiple longitudinal studies found that self-esteem was not a significant predictor of later substance use (e.g., Block, Block, \& Keyes, 1988; Stein, Newcomb, \& Bentler, 1987). Second, intrapersonal theories conceptualize individual factors as direct predictors of substance use while other findings suggest that these individual features are more distal factors (Stacy, Newcomb, \& Bentler, 1991). For example, intrapersonal characteristics influence substance-related cognitions, which actually predict substance use (Petraitis, Flay, \& Miller, 1995). Additionally, intrapersonal characteristics may only partially explain drug use. Indeed, youth who experience academic difficulties or low selfesteem may not smoke or drink (Scheier, Botvin, \& Miller, 2000; Wills, Sandy, Shinar, \& Yaeger, 1999). Unfortunately, the sole reliance on variables such as self-esteem may preclude a comprehensive understanding of why youth do or do not use substances. In conclusion, there is a lack of evidence to support the reliance on intrapersonal characteristics as the primary predictors of adolescent substance use. Moreover, these variables may explain only one component of substance use; additional constructs (e.g., family relationships, substance-specific attitudes) and a broader range of intrapersonal variables (i.e., more than just self-esteem and academic difficulties) might be necessary to completely explain teenage drug use.

Problem Behavior Theory. All of the previous theories each used different constructs (cognitions, social influences, individual characteristics) as the core explanation of health behaviors. However, none of the theories were able to fully conceptualize substance use. To address this limitation, integrative models that incorporate all types of variables have been 
proposed. Problem Behavior Theory (PBT) is one such model that attempts to explain substance use and other deviant behaviors (Jessor, 1991; Jessor \& Jessor, 1977). The most recent iteration of PBT (see Figure 3) groups variables into five inter-related constructs: biology/genetics (e.g., family history of substance abuse), social environment (e.g., SES, urban/rural residence), perceived environment (e.g., deviant role models, perceived parent/peer approval), personality (e.g., self-esteem, sensation-seeking), and behavior (e.g., use of other substances, academic performance; Jessor, 1991). These constructs then predict engagement in deviant behaviors and subsequent health problems. Major risk factors for adolescent substance use include concurrent substance use, poor attachment with parents, associations with deviant peers, positive expectancies regarding substance use, low self-esteem, and low academic achievement (Jessor, 1991).

Past studies provide evidence that support the use of PBT in predicting adolescent substance use. Conduct problems and behavior dysfunction were related to earlier age of cigarette initiation (Lambert \& Hartshough, 1998). Another study that incorporated PBT in its design found that cigarette smoking and alcohol use were risk factors of problematic eating behaviors, while positive self-esteem, good academic performance, and family attachment were significant protective factors (Croll, Neumark-Sztainer, Story, \& Ireland, 2002). Other studies also found that variables included in PBT (e.g., depression, substance use) predicted initiation of sexual activity as well as engagement in unsafe sexual behavior (Lammers, Ireland, Resnick, \& Blum, 2000; Shrier, Harris, Sternberg, \& Beardslee, 2001). Given that PBT helps explain other forms of adolescent substance use, this theory may also explain adolescent e-cig use; however, no studies have explicitly tested this application. 
As with the other theories, there are some potential limitations of PBT. One of the main critiques of this model is that it places less emphasis on the influence of thoughts on adolescent substance use (Petraitis et al., 1995). However, those same authors note that PBT accounts for a substantial amount of variance in substance use behaviors, and the addition of more cognitive variables would only strengthen the model. A second criticism is that PBT does not posit the mechanism by which more distal variables, such as relationships with parents, influence substance use. While this is problematic, more advanced statistical techniques (e.g., structural equation modeling) may permit the exploration of these paths in predicting teen use of substances.

Summary of Theories of Substance Use. Taken together, there are a number of theories that can help explain substance use behaviors. Each model has particular strengths and weaknesses to consider when applying them to certain health or problem behaviors. To help better understand the growing phenomenon of electronic cigarette use in adolescents, it is beneficial to apply these theories. Problem Behavior Theory, in particular, is one approach that appears to hold great promise in explaining the use of vapor products because it incorporates a wide variety of factors (e.g., social, psychosocial, cognitive) that may relate to substance use. Furthermore, initial research suggests that variables included in PBT may be associated with ecig use in teens. For example, one consistently reported finding is that simultaneous use of conventional cigarettes is a strong predictor of adolescent e-cig use (e.g., Camenga et al., 2014; Wills, Knight, Williams, Pagano, \& Sargent, 2015). PBT is the only model reviewed so far that incorporates concurrent substance use and thus may be an exceptionally potent predictor of use of e-cigs. Additionally, Wills and colleagues (2015) found that adolescent use of electronic cigarettes was significantly associated with three variables that are part of PBT (parent- 
adolescent conflict, rebelliousness, and sensation-seeking). Finally, because research on electronic cigarettes is so new, it is important to consider a substantial range of potential influences (e.g., cognitive, environmental, personal) and the breadth of PBT will be useful in guiding that approach.

\section{Applying Problem Behavior Theory to Adolescent e-Cigarette Use}

Studies have used isolated components of PBT, with preliminary findings indicating that these PBT variables are strong predictors of vaping in teens (e.g., Sutfin, McCoy, Morrell, Hoeppner, \& Wolfson, 2013; Wills et al., 2015). These variables are separated into five general constructs: (1) biology/genetics, (2) social environment, (3) perceived environment, (4) personality, and (5) behavior.

\section{Biology/Genetics}

Some evidence suggests that there is a genetic component related to tobacco use and nicotine dependence. A study examining the heritability of substance use among 626 17-year-old pairs of twins found a strong genetic component to tobacco use and nicotine dependence (McGue, Elkins, \& Iacono, 2000). Similarly, Kendler and colleagues (2012) examined genetic and family environmental influences on drug abuse in Swedish children and their adoptive families (Kendler et al., 2012). Results indicated that biological parental and sibling hospitalizations related to alcohol abuse and dependence predicted children's risk for drug abuse (Kendler et al., 2012). Moreover, indices of genetic risk (e.g., biological parent treatment for drug abuse) remained a significant predictor of youth drug abuse even when environmental influences were included in statistical analyses. Unfortunately, studies on family histories of drug use and dependence have not been applied to adolescents' use of electronic cigarettes. Because these devices are substantially different than other substances (e.g., efficiency of nicotine 
delivery, inclusion of different chemical compounds), it is not clear if genetic influences will generalize. Indeed, there is evidence that family history of substance use was a weak predictor of using illicit substances, such as marijuana, among male and female adolescent twins (McGue et al., 2000). Consequently, there is a need to examine whether use of electronic cigarettes is influenced by heritable risk for substance use.

Taken together these studies suggest that genetic and biological factors may play an important part in explaining adolescents' use of electronic cigarettes. Specifically, family histories of substance use and dependence may represent a risk factor for adolescent drug use (e.g., Kendler et al., 2012). However, no known studies have examined how genetic and biological factors relate to use of electronic cigarettes. Therefore, it is necessary to explore if biological and genetic factors are associated with use of electronic cigarettes in teens.

\section{Social Environment}

The social environment construct captures the family and community variables that could potentially influence deviant behaviors. Social risk factors in PBT have included poverty, racial inequality, and family cohesiveness, among other demographic or environmental variables (Jessor, 1991). Many of these variables have been related to adolescent substance and electronic cigarette use. Indeed, demographic factors such as race/ethnicity, socioeconomic status (SES), and family structure are associated with adolescent use of conventional cigarettes (Tyas \& Pederson 1998). Camenga and colleagues (2014) also found that Caucasian students were over three times more likely to have used an e-cig in the past 30 days when compared with non-white students. Conversely, another study found that a smaller proportion of Caucasian teens used electronic cigarettes compared with Asian Americans, Filipinos, and Native Hawaiians (Wills et al., 2015). Although demographic factors have been identified as significantly associated with 
the use of electronic cigarettes, these studies possess some limitations. First, some studies involved international samples (e.g., Goniewicz \& Zielinska-Danch, 2012). Socialenvironmental differences between these countries and the United States (e.g., availability of resources) may inhibit generalizability of the findings to samples of American high school students. In addition, many of these studies did not include variables aside from demographics (e.g., Camenga et al., 2014a; Goniewicz \& Zielinska-Danch, 2012). Therefore, it is not clear how these social-environmental variables work in conjunction with other variables (e.g., social influences, psychosocial variables) in predicting e-cig use in youth.

Residence or community type (e.g., urban/rural/suburban) also is particularly important when considering adolescent substance use. Rural teens are at the greatest risk to engage in health-risk behaviors, such as smoking, alcohol use, and unsafe sex (Atav \& Spencer, 2002). Indeed, in more rural states, such as West Virginia and Kentucky, smoking rates remain significantly higher than the rest of the country (CDC, 2013). In contrast, investigators reported that Polish teens living in an urban area were more likely to have used e-cigarettes in the past 30 days than rural teens (Goniewicz et al., 2012). However, the authors noted that rural teens may have been under-represented in that study. Moreover, their sample consisted of adolescents and young adults from Poland. Rural and urban residences in Poland may not be directly comparable with similar communities in the United States. In addition, there is some evidence to suggest that types of risk factors for health-risk behaviors may differ by type of residence (Bean et al., 2008). Studies reported conflicting results in predictors of substance use depending on the type of community (i.e., suburban or urban) participants live in (Botvin et al., 1993; Esptein, 2003). However, all of these studies focused on health-risk behaviors such as obesity and use of conventional cigarettes. A recent study (Owusu et al., 2016) showed that lifetime (35\%) and 
current $(11 \%)$ e-cig use in rural areas is congruent with national prevalence (38\%; Kann et al., 2016). However, no studies have explicitly examined if community type (i.e., urban/suburban/rural) represents a unique risk factor for e-cig use. Altogether, these results suggest that it is imperative to consider how residence/type of community relates to substance use, including electronic cigarettes.

There is also evidence that gender may be related to use of electronic cigarettes. Gender differences exist in risk factors for and rates of tobacco use (Harrell, Bangdiwala, Deng, Webb, \& Bradley, 1998; McKee et al., 2003). Similarly, multiple studies found that males are significantly more likely to use vapor products (Cho, Shin, \& Moon, 2011; Goniewicz \& Zielinska-Danch, 2012; Lee, Grana, \& Glantz, 2014; Ramo, Young-Wolff, \& Prochaska, 2015). However, most of these studies sampled from international populations (Cho et al., 2011; Goniewicz \& Zielinska-Danch, 2012; Lee et al., 2014). Furthermore, not all studies were restricted to adolescents (Goniewicz \& Zielinska-Danch, 2012; Ramo et al., 2015). Therefore, it is not clear if these results will apply to high school students in the United States. Moreover, no studies have examined potential reasons why gender influences use of electronic cigarettes (e.g., differences in risk or protective factors). Although gender is biologically determined, differences may be due to environmental or social influences rather than biological factors. Indeed, conclusions from some studies suggest that differences in cigarette use and quitting may be attributable to more socio-cultural or environmental variables (e.g., fear of gaining weight; Pirie, Murray, \& Luepker, 1991) that happen to be gender-related. To fully characterize adolescent use of e-cigs, it is necessary to examine the interrelation between gender, risk factors, and actual use of electronic cigarettes. 
Social-environmental variables represent one of the core factors to consider when evaluating risks of substance use behavior. There is consistent evidence of their utility in predicting a variety of health-risk behaviors, including the use of electronic cigarettes (e.g., Lee et al., 2014; Tydas \& Pederson, 1998). Furthermore, area of residence/type of community appears to be an essential variable in understanding any substance use behavior (Atav \& Spencer, 2002; Goniewicz et al., 2012). Though these variables cannot be changed, for the most part, they can serve as guides for where and how prevention efforts might be applied.

\section{Perceived Environment}

In PBT, the perceived environment construct attempts to capture adolescents' beliefs about the risks and benefits of engaging in a certain behavior. Common variables include parent or peer approval of substance use, and models for deviant behavior. A novel variable that may play a role in the perceived environment relevant to e-cigarette use is the marketing strategies and product characteristics of these devices.

Family and Peer Influences. Associations between family/peer variables and use of electronic cigarettes have been observed. Results from two studies indicated that youth are more likely to use electronic cigarettes if they live with a family member who smoked (Goniewicz \& Zielinska-Danch, 2012) or if their parents owned an e-cig (Pentz et al., 2015). In addition, findings from a recent study by Wills and colleagues (2015) suggest that peer smoking predict use of electronic cigarettes. Conversely, an older study failed to find a significant association between social influences and use of electronic cigarettes (Cho et al., 2011).

These studies suggest that family members and peers may influence use of electronic cigarettes. Specifically, youth may be more likely to use electronic cigarettes if they have peers and parents who smoke (e.g., Goniewicz \& Zielinska-Danch, 2012), or if their parents own an e- 
cig (Pentz et al., 2015). However, these studies have had mixed findings as well as methodological concerns that may limit the ability to confidently draw conclusions. First, many of these studies measure peer or family influences with only one item (Goniewicz \& ZielinskaDanch, 2012; Wills et al., 2015). Because of this, the construct validity is questionable. Second, these studies do not use multivariate approaches to examine how peer and family variables work together to predict use of electronic cigarettes (Pentz et al., 2015; Wills et al., 2015). To address these limitations, future studies should use more encompassing assessment of parent and peer influence and apply multivariate statistical approaches to better understand predictors of e-cig use in youth.

Product Characteristics. Unique aspects of the electronic cigarette phenomenon are its advertising and product characteristics. Manufacturers promote these products as healthy alternatives to regular cigarettes despite some recent evidence to the contrary (e.g., Goniewicz et al., 2014). Moreover, companies tout vapor products as modern or "hip" (Grana \& Ling, 2014). A review of e-cig advertising by Williams and Knight (2015) found that manufacturers are using the same strategies previously used to promote regular cigarettes. For instance, multiple celebrities have endorsed these products. Therefore, youth are regularly exposed to the messages of these advertisements and could potentially perceive these products as healthy, trendy, and popular in society.

Another unique property of vapor products is the potential use of flavored e-liquids. Vaporfi, an online e-cig supply store, advertises having over 30,000 different flavors, including tobacco, menthol, dessert, and fruit varieties (Vaporfi, 2015). These flavors may serve to attract new users, including adolescents (Etter \& Bullen, 2011). Interestingly, tobacco flavors appear to initiate e-cig use among former and current adult smokers, while non-tobacco flavors (e.g., fruit, 
dessert) may maintain e-cig use among former smokers (Farsalinos et al., 2013). The inclusion of flavored e-liquids is reminiscent of other tobacco products. Specifically, the chewing tobacco industry used flavored products to initiate use and graduate users towards more nicotine-heavy products (Marsee v. United States Tobacco Co., 1986).

Electronic cigarettes possess many unique characteristics that may influence product attractiveness and use in addition to other variables (e.g., attitudes, social norms). Because of this, it is important to consider these characteristics when trying to better understand what factors contribute to adolescent e-cig use. Unfortunately, no known research has examined if these product factors predict use of vapor products. Because the characteristics and marketing of these products have received attention, future studies should examine how these variables act as correlates for adolescent use of electronic cigarettes.

\section{Personality}

The personality construct of PBT aims to evaluate and integrate adolescent characteristics that may predict substance use behaviors. Relevant variables include attitudes and expectancies regarding substances, self-efficacy to resist or engage in substance use, attitudes towards school, and sensation-seeking.

Attitudes and Expectancies. Attitudes towards electronic cigarettes are of particular interest as attitudes/beliefs have been associated with use of other substances (e.g., regular cigarettes, alcohol; Hawkins, Catalano, \& Miller, 1992; Tyas \& Pederson, 1998). Results from a focus group of 47 high-school teens from the southwestern United States suggest that adolescents perceive e-cigarettes as being less harmful and more socially desirable than conventional cigarettes as well as posing less risk of being caught for using when not permissible (Peters, Meshack, \& Lin, 2013). However, the focus groups consisted of African American and 
Hispanic American teenagers between the ages of 15 and 17, which is rather narrow in scope. Furthermore, participants volunteered to participate; therefore, the generalizability of these findings may be limited due to sample characteristics, such as race, age, and willingness to voluntarily discuss use of electronic cigarettes. In addition, the majority of teens sampled in a Polish study believed that electronic cigarettes were healthier than regular cigarettes (Goniewicz et al., 2012). As mentioned previously, this sample's characteristics may limit the generalizability of their findings, however. Another study found that a majority of U.S. teens believed that any health risks from e-cigs were dose-dependent, and one-third thought they were less harmful than regular cigarettes (Ambrose et al., 2014). Wills and colleagues (2015) also found that teens who used electronic cigarettes had more positive attitudes and beliefs regarding the products. Finally, results from a recent study indicate that more positive and fewer negative attitudes towards electronic cigarettes are associated with intention to use and reported ever-use of vapor products (Chaffee et al., 2015). These findings are similar to what has been observed in adult samples; that is, electronic cigarettes are viewed as having fewer costs and more benefits than regular cigarettes (Harrell et al., 2014; Sutfin et al., 2013).

Although beliefs regarding electronic cigarettes were repeatedly associated with use, these studies have notable limitations. First, all of the aforementioned studies incorporated extensively modified questionnaires (e.g., used only one item from each subscale) or used a limited number of questions (i.e., one or two) to assess attitudes towards e-cigs. Therefore, the psychometric properties of the measure are not known, which raises potential threats to experimental validity. Furthermore, some of the studies utilized samples from different countries (Goniewicz \& Zielinska-Danch, 2012), the non-continental U.S. (Wills et al., 2015), or were comprised primarily of minorities (Peters et al., 2013), which may restrict generalizability of 
findings to other populations in the United States. These methodological limitations preclude firm conclusions regarding the association between attitudes/beliefs and teens' use of electronic cigarettes. Future research should address these limitations by using samples from the United States that are more representative of the general population and also assess constructs with standardized measures.

Self-Efficacy. In addition to attitudes and expectancies, self-efficacy to use or resist using substances has been observed as an important explanatory variable (De Vries, Dijkstra, \& Kuhlman, 1988; Lawrance, 1989). One study recruited 85 adolescents between the ages of 14 and 17 to examine self-efficacy as a predictor of conventional cigarette smoking behavior (De Vries et al., 1988). Their results suggested that self-efficacy was a significant predictor of intention to smoke and actual smoking behavior. Moreover, this study found that smokers reported greater difficulties in resisting smoking than did non-smokers. Although this study possessed many strengths (e.g., diverse sample, use of multivariate analyses), there were some limitations. Specifically, the study was cross-sectional in design, preventing conclusions regarding possible casual relations between variables. Indeed, it is possible that differences in self-efficacy are the result of rather than an antecedent to smoking behaviors in youth.

More recent studies of self-efficacy report similar findings. Results from a study by Kremers, Mudde, and de Vries (2001) suggested that smoking self-efficacy differed significantly by smoking status (e.g., never smoker, experimenter, regular smoker), with never smokers exhibiting the highest self-efficacy and regular smokers reporting the lowest self-efficacy. Findings from a different study found that smoking self-efficacy increased as adolescents went through a smoking cessation program (Patten et al., 2008). Despite the strengths of these studies (e.g., longitudinal design, large sample size), there are some notable weaknesses. First, the study 
by Kremers and colleagues (2001) was cross-sectional. Second, the study by Patten and colleagues (2008) utilized a sample of adolescents that were motivated to quit smoking. Therefore, it is possible that their smoking self-efficacy may be different from youth who do not intend to quit using tobacco.

Overall, these studies suggest that smoking self-efficacy is an important predictor of adolescent substance use (Kremers, Mudde, \& de Vries, 2001; Lawrance, 1989). However, there are some methodological flaws that limit the ability to confidently interpret results. To address these concerns, future studies should be longitudinal in nature and recruit a more diverse sample of adolescents. Finally, no studies have applied self-efficacy as a predictor of electronic cigarette use in adolescents. Therefore, it is not known if similar associations exist. Because self-efficacy is an important predictor of other substance use behaviors, it is important to incorporate this construct when exploring predictors of adolescent e-cig use.

School-Related Variables. Academic variables have also been implicated as a predictor of substance use among adolescents. In his review on psychosocial risk factors of alcohol initiation, Donovan (2004) noted that lower academic achievement and negative attitudes towards school were associated with an increased likelihood of alcohol use in middle and high school students. Similarly, a review by Tyas and Pederson (1998) stated that poor academic performance and low academic aspirations were associated with an increased likelihood of tobacco use. Academic variables were also associated with adolescent e-cig use. Specifically, low satisfaction in school (Cho et al., 2011) and low academic performance (Wills et al., 2015) were associated with higher rates of adolescent e-cig use.

While these studies all suggest that academic performance and satisfaction with school are related to substance use, there are some limitations that must be acknowledged. First, 
relatively few studies (Cho et al., 2011; Wills et al., 2015) have focused on electronic cigarettes. Therefore, it is not clear if the findings from other substance literatures (i.e., Donovan, 2004; Tyas \& Pederson, 1998) are generalizable to electronic cigarettes. Moreover, the early studies on electronic cigarettes possess some potential flaws. For instance, the study by Cho and colleagues (2011) found low rates of e-cig use (approximately $0.5 \%$ ). Therefore, these youth may represent outliers or exceptionally deviant teens. Since this study, rates of e-cig use have dramatically increased (e.g., Kann et al., 2016), which may indicate that these products are less deviant and more readily accepted. Finally, Wills and colleagues (2015) only assessed academic involvement, while previous literature focused on performance in and attitudes towards school. Because of these weaknesses, it would be beneficial to re-examine how academic variables relate to use of electronic cigarettes. Specifically, future studies may wish to incorporate a wider range of school-related variables (e.g., attitudes toward school, attitudes toward teachers, and academic performance) within a diverse sample.

Sensation-Seeking and Impulsivity. Another set of personality variables that have been associated with substance use is sensation-seeking and other measures of impulsivity. Wills and colleagues (2015) found that youth who reported high levels of sensation-seeking were more likely to use electronic cigarettes than youth with lower sensation-seeking. However, a notable limitation of this study is that the investigator created the measures used in the study. Because psychometric properties are not readily available, it is difficult to establish the reliability and validity of these instruments, which raises concerns about drawing accurate conclusions. Results from another study also suggest that executive functioning deficits (e.g., increased impulsivity, poor planning) predict e-cig behavior above and beyond demographic variables, such as age, gender, and ethnicity (Pentz et al., 2015). However, some researchers believe that the executive 
functioning measure used in this study actually assesses overall problem behavior, which raises concerns about the authors' interpretation of findings and conclusions. Future research should consider employing standardized measure of sensation-seeking and impulsivity because of the questionable nature of the instruments used in previous studies exploring predictors of e-cig use in youth.

\section{Behavior}

One of the core assumptions of PBT is that all deviant behaviors are strongly correlated with one another; for instance, engagement in one substance use behavior predicts engagement in others (Jessor, 1991). Adolescent electronic cigarette use supports this assumption as it is associated with other substance use behaviors (e.g., drinking alcohol, smoking marijuana), and smoking traditional cigarettes is repeatedly identified as the strongest correlate of electronic cigarette use (Camenga et al., 2014; Dautzenberg et al., 2013; Lee et al., 2014; Lessard et al, 2014). Furthermore, Lee and colleagues (2014) found that youth who had made an attempt to quit cigarettes in the past 12 months were over 1.5 times as likely to try an electronic cigarette.

Overall, the high rates of dual use suggest that many youth are using vapor products as substitutes for regular tobacco products. Interestingly, there is a small portion of youth who only used electronic cigarettes (Wills et al., 2015). Moreover, significantly more adolescents tried electronic cigarettes but did not use conventional cigarettes when compared with adults (CarrollChapman \& Wu, 2014). This suggests that although concurrent substance use is still a risk factor for adolescent e-cig use, researchers should also consider the role other variables play. Unfortunately, most of the literature (e.g., Camenga et al., 2014; Cho et al., 2011) has focused on demographics (e.g., gender, age) and has not considered constructs routinely incorporated within theoretical models that explain other adolescent substance use behaviors (e.g., attitudes towards 
substances, peer modeling). To develop an adequate understanding of adolescent use of electronic cigarettes, future studies should use theoretical models to guide study design and select relevant variables, including an array of behavioral risk factors (e.g., use of other substances).

\section{Summary and Critique of the Literature}

Electronic cigarettes are novel nicotine delivery devices that have experienced growing popularity and dissemination over the past decade, including with adolescents (e.g., Kann et al., 2016; Yamin et al., 2010). Because of legal loopholes, manufacturers have been able to advertise their products in ways that resemble old conventional cigarette ads (Williams \& Knight 2015). This approach has exposed a large portion of the population to these novel tobacco products and has the potential to renormalize nicotine use (Cataldo, et al., 2015; CDC, 2013; Duke, 2014; Durmociz, 2014; Peters, Meshack, et al., 2013).

There are some potential concerns regarding the short- and long-term health effects of electronic cigarettes (Harrell, Simmons, Correa, Padhya, \& Brandon, 2014; Vardavas et al., 2012). Overall, evidence regarding the safety of e-liquids and vapor is mixed. Some toxic byproducts were identified (Behar et al., 2014), but at lower levels than regular cigarettes (Goniewicz et al., 2014). Consequently, the potential health effects are not well understood. Although there is some evidence of short-term adverse effects in pulmonary functioning, there is no information regarding the potential long-term health effects of electronic cigarettes (Harrell et al., 2014). Overall, e-cigs cannot be declared completely harmless, but there is support behind their use as a harm reduction product for replacing conventional cigarette smoking (Bhatnagar et al., 2014). However, a dramatic increase in the number of adolescents who have ever used or currently use electronic cigarettes regularly has raised substantial concerns (CDC, 2013; Wills et 
al., 2015). Because e-cigarette use has only become problematic over the past few years, there is relatively little research on risk factors for adolescent use. However, models and theories of other substance use behaviors (e.g., Theory of Planned Behavior, Social Cognitive Theory, and Intrapersonal Theories) can be applied to help explain teenage experimentation with electronic cigarettes. The Theory of Planned Behavior (TPB) emphasizes the importance of substancespecific attitudes/beliefs, social norms, and perceived behavioral control to predict behavioral intentions and actual behaviors (Azjen, 1985; 1988). Although the TPB has received considerable attention in other literatures (e.g., Guo et al., 2007), there is some evidence to suggest that it may not be an ideal theoretical framework for health-risk behaviors, such as adolescent use of e-cigs (McEachan et al., 2011). Similarly, Social Cognitive Theory (SCT) has been successfully applied to other substance use behaviors (Bailey \& Hubbard, 1990). However, there is some disagreement as to whether peer influence is an antecedent or consequence of substance use behaviors (Fisher \& Bauman, 1988; Simons-Morton \& Farhart, 2010). Finally, intrapersonal theories posited that individual characteristics, such as self-esteem, were strong predictors of substance use (Kaplan et al., 1982). Nonetheless, most evidence does not support the utility of individual characteristics alone in predicting substance use (e.g., Block et al., 1988). All of these previously discussed approaches focused on the importance of cognitive (TPB), social (SCT), and individual (intrapersonal theories) characteristics. However, none of these conceptual frameworks appears capable of adequately explaining adolescent use of electronic cigarettes. Problem Behavior Theory is a more comprehensive model that incorporates cognitive, social modeling, and intrapersonal influences when conceptualizing adolescent substance use (Jessor, 1991). There is some support for the utility of this model in predicting adolescent smoking and sexual activity (Shrier et al., 2001). Because research on electronic 
cigarette use is in its infancy, Problem Behavior Theory may be more advantageous than other models given its focus on a broad range of potential risk factors. Furthermore, there is some initial evidence that some variables included within PBT (e.g., environmental, attitude, behavior) predict adolescent use of electronic cigarettes (Wills et al., 2015).

Overall research on adolescent use of electronic cigarettes is relatively limited. Certain characteristics of vapor products (e.g., flavored liquids, advertising strategies) may increase the likelihood of use in adolescents (Grana \& Ling, 2014). Youth are also more likely to use vapor products if they are male, older, or have family members who smoke (Carroll-Chapman \& Wu, 2014). Furthermore, there is evidence that adolescents and young adults from urban residences may be more likely than rural youth to use e-cigs (Goniewicz \& Zielinska-Danch, 2012). Concurrent substance use (e.g., tobacco, alcohol) and positive attitudes towards electronic cigarettes also predict use of vapor products (Carroll-Chapman \& Wu, 2014; Pepper et al., 2013). Finally a number of psychological variables, such as sensation-seeking, parent-adolescent relationship (e.g., parental support and monitoring, parent-adolescent conflict), and lower academic performance are associated with use of electronic cigarettes (e.g., Cho et al., 2011; Wills et al., 2015).

Although there are some consistent findings regarding risk factors of adolescent substance use, there are some methodological limitations in the current literature. First, only one study applied theoretical models to guide the hypotheses and selection of study variables (Wills et al., 2015). Because of this, many potential influences (e.g., attitudes/beliefs, social influences) in teen use of e-cigarettes received little attention, despite these being important predictors of other youth health behaviors. Second, many studies have not used standardized measures to assess variables of interest. For instance, Wills and colleagues (2015) used only one item to 
measure perceived health effects of e-cigs. This practice was repeated across many other studies (e.g., Cho et al., 2011; Pepper et al., 2013). Therefore, the reliability and validity of the measures used in much of the literature is unknown; this is a significant threat to the experimental validity, which can limit the conclusions that are drawn. Finally, few of the reviewed studies utilized multivariate statistics. Instead, some authors repeatedly used univariate tests (e.g., Wills et al., 2015), which can inflate the risk of committing a type I error. Together, these limitations indicate the need for studies in adolescent e-cigarette use that are thoughtfully planned and rooted in theory, use standardized and psychometrically sound assessments, and employ multivariate statistical analyses.

\section{Aims and Hypotheses}

The overall objective of the current study is to characterize the risk factors of adolescent use of electronic cigarettes. The proposed project will consist of two specific aims.

Aim 1. The first and primary aim of this study is to evaluate the utility of Problem Behavior Theory (PBT) in predicting adolescent use of electronic cigarettes. Based on the review of the current literature, variables will be assigned to the five different constructs of PBT (genetic/biologic, social environment, perceived environment, personality, and behavior) (see Figure 4), as described below.

Genetic/Biologic. Results from previous studies suggest that familial history of substance dependence represents a key genetic risk factor for adolescent substance use that is distinct from other environmental and social influences (e.g., parental modeling; Kendler et al., 2012). Therefore, the genetic/biologic latent variable will be comprised of reported drug dependence in the immediate and extended family. 


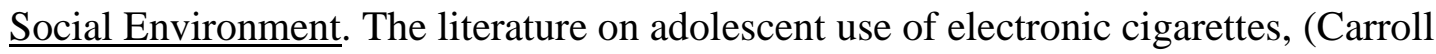
Chapman \& Wu, 2014; Wills et al., 2015), tobacco (Tyas \& Pederson, 1998), and other substances (Atav \& Spencer, 2002; Donovan, 2004) all regularly report that demographic risk factors include sex, and family sociodemographic factors (e.g., education, marital status, urban or rural residence, and SES). Consequently, the social environment construct will be comprised of SES, community type, parent marital status, and participant sex. Although sex is biologically determined, research suggests that gender differences in smoking behavior are largely attributed to social-environmental factors (e.g., Pirie et al., 1991).

Perceived Environment. Perceived environment will be composed of substance use modeling of smoking behaviors and product characteristics of electronic cigarettes. Research suggests that adolescent may substance use may be influenced when parents and peers model smoking. Specifically, youth may be more likely to use substances if they see their parents and peers engaging in similar behaviors (e.g., using tobacco products; (Flay et al., 1994; Wills et al., 2015 ) or if peers and parents express more positive attitudes towards drugs (Berkowitz \& Perkins, 1986; Perkins, 2002; Peters et al., 2013). Furthermore, some authors have hypothesized that teens may be more likely to use an e-cig when they are exposed to more advertisements about e-cig products (Duke et al., 2014)

Personality. The personality component of the proposed model will be comprised of selfefficacy to resist using an e-cig, expected costs/benefits, and symptoms of inattention/hyperactivity. Research on conventional tobacco use has found that adolescents' selfefficacy to resist smoking cigarettes was associated with initiation and continuation of cigarette use (De Vries et al., 1988; Lawrance, 1989). Similarly, reports suggest that adolescents' perceived costs and benefits of substance use was related to actual substance use (Hine, Honan, 
Marks, \& Brettschneider, 2007; Wills et al., 2015) Additionally, symptoms of hyperactivity and attention problems have repeatedly been reported as predictors of substance use in youth (e.g., Donovan, 2004; Elkins, McGue, \& Iacono, 2007), including electronic cigarettes (Wills et al., 2015).

Behavior. In the fifth and final component, alcohol, tobacco, and marijuana use, as well as average grades will form the behavior latent variable. Concurrent substance use has been reported as one of the strongest predictors of use of electronic cigarettes (Cho et al., 2011; Lee et al., 2014; Wills et al., 2015). Furthermore, academic achievement has been related to alcohol (Donovan, 2004) and tobacco use (Tyas \& Pederson, 1998) in adolescents.

It is hypothesized that the combination of all PBT variables will significantly predict adolescents' use of electronic cigarettes. Furthermore, it is hypothesized that individual constructs will significantly predict use of electronic cigarettes.

Aim 2. The second aim of this study is to examine how risk factors predict group membership for different e-cig use categories (i.e., never, lifetime-only, and past 30-day users). Results from studies investigating the initiation of tobacco use among adolescents (e.g., Hu, Campbell, \& Flay, 2000; Pierce, Choi, Gilpin, Farkas, \& Merritt, 1996) suggest that risk factors differ by smoking stage (e.g., never vs. experimental vs. regular). There is evidence of differences in levels of risk factors between adolescents who have never used an e-cig, use only an e-cig, and use both electronic and conventional cigarettes (Wills et al., 2015). However, no studies have explored differences in risk factors among youth that have never used an e-cig, have not used one in over a month, and have used one in the past 30 days. Based on the trends found in the e-cig and general tobacco literatures, it is hypothesized that youth that have used an electronic cigarette in their life, but not in the past 30 days, will report higher levels of risk 
factors (e.g., attitudes towards electronic cigarettes, self-efficacy to resist using an e-cig) than teens that have never used a vapor product. Furthermore, it is hypothesized that teens that used an e-cig in the past 30 days will report higher levels of risk factors than teens who have not used a vapor product in the last month.

\section{Method}

\section{Participants}

A total of 522 high school students were recruited from schools in West Virginia, suburban Ohio, and Pennsylvania, and one adolescent medicine clinic. The adolescent medicine clinic was added in an effort to include more diverse and high-risk youth in the sample, as many of these teens present as medically complex or report engaging in high-risk health behaviors (e.g., substance use). Twenty-seven percent $(n=141)$ of the sample came from the school in suburban Ohio, 39.7\% $(\mathrm{n}=207)$ were recruited from suburban $\mathrm{WV}, 17.2 \%(\mathrm{n}=90)$ were recruited from rural $\mathrm{WV}, 8.2 \%(\mathrm{n}=43)$ were recruited from a school in rural PA, and 7.9\% $(\mathrm{n}=$ 41) were recruited from the adolescent medicine clinic. Inclusion criteria included youth who:

(1) were enrolled in a high school; (2) were between 13 and 18 years old; and (3) spoke English (questionnaires are only validated in English). Exclusion criteria included individuals with significant cognitive impairments that could limit their ability to independently complete questionnaires. Youth with possible cognitive impairment were identified by teachers (school sites) and medical staff (clinic site).

\section{Procedure}

Approvals from the Institutional Review Board at West Virginia University and the administration of participating schools were obtained before recruiting participants and collecting data at both school and clinic sites. 


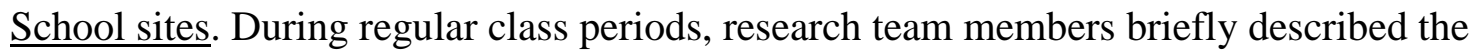
study, including participation requirements, and potential risks and benefits. Informed consent forms and recruitment letters describing the study were distributed to all students. Youth were encouraged to sign the form and obtain their parent signature, regardless of whether they provided assent (youth aged 11-17 years) and consent (parent and youth aged 18 years) to take part in the study. This procedure was used to enhance integrity in calculating refusal rates and has been used in previous studies (i.e., Chartier et al., 2008). Five to seven days after distributing recruitment materials, research team members returned to classrooms to collect signed consent forms. Youth who returned fully signed consent forms (regardless of participation in the study) were entered into a lottery for a chance to win one of ten $\$ 20$ gift cards. Names were drawn once all participants were recruited to ensure equal chances of winning.

After obtaining consent and assent, participating students were given a copy of a blank consent form to take home. They completed a packet of questionnaires that included the following measures: (1) Participant Information Form; (2) Youth Risk Behavior Survey; (3) Smoking Expectancy Scale for Adolescents; (4) Smoking Self-Efficacy Questionnaire; and (5) MINI-IPIP; (6) Brief Sensation-Seeking Scale Adolescent Version; (7) Parental Control Measure; (8) Parental Knowledge Measure; (9) Parental Solicitation Measure; Youth Disclosure Scale - Disclosure; (11) Youth Disclosure Scale-Secrecy; and (12) Conflict Behavior Questionnaire. Youth completed the questionnaire packet during their regular class periods. Upon completion of the questionnaires, youth were entered into a lottery (separate from the one for simply returning signed consent/assent forms) for a chance to win one of fifty $\$ 20$ gift cards. Names were drawn once the full sample was collected to ensure equal chances of winning. 


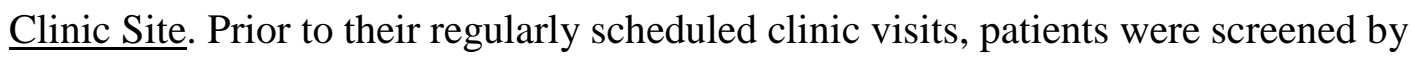
medical team members affiliated with this study to identify youth who met the study eligibility criteria. Once prospective participants were identified, a physician or nurse approached the patient and family and provided a brief description of the study. If the patient was interested in participating, a member of the research team provided a detailed description of study procedures, risks, and benefits, and obtained written consent from parents and youth aged 18 years and assent from patients aged 11-17 years. Participants completed a packet of questionnaires in their private clinic room (the same packet was used for clinic and school sites). Youth were required to complete the packet before they left clinic that day. Patients were instructed to sit away from their parents to complete measures independently. Participants who completed questionnaires were entered into the same lottery as participants recruited from schools.

\section{Measures}

Planned Behavior Theory, as outlined by Jessor (1991) utilizes of five different constructs ([1] genetics/biology, [2] social environment, [3] perceived environment, [4] personality, and [5] behavior) to predict adolescent health-risk behavior. Several factors were assessed to tap the different latent variables proposed by PBT (see Figure 4). The influence of genetics and biology were measured via indices of familial substance dependence. Demographic (e.g., SES) and family-systems variables (e.g., parent marital status) were used to capture the construct of social environment. Modeling of smoking behavior as well as exposure to e-cig advertising were used to evaluate perceived environment. Next, the personality variables included self-efficacy to resist using e-cigs, expected costs and benefits of e-cig use, sensation seeking, and extraversion. Finally, adolescent concurrent substance use and academic performance characterized potential behavioral correlates of e-cig use. Table 1 displays all 
variables included in the proposed PBT model, how they were coded, and the measures from which they were taken. Specific measures used to obtain this information are described below. Student Information Form (SIF). The Student Information Form was created for this study to obtain demographic information to describe the sample and include in the model. This measure included items pertaining to participant age, gender, and ethnicity, as well as family residence and socioeconomic variables. This brief survey also asked the adolescent to report on family history of and treatment for drug dependence, including nicotine.

Model variables (Table 1) were coded such that higher scores represent higher risk. Population density was obtained using census data for the participants' zip codes. Percent of free school lunches provided to students were obtained from a public database (Office for Civil Rights, 2016) and used as a measure of school-level socio-economic status (SES). Additionally, youth reported drug dependence among immediate and extended family members $(0=n o, 1=$ yes). Participants indicated what best described their parents' current marital status (e.g., separated, married to other biological parent, divorced/single). These response options were recoded to indicate whether the family consisted of (1) two adults, biological parents (i.e., intact family), (2) two parents, non-biological/step-parents (i.e., blended family), or (3) unmarried, divorced, or widowed adult(s) (i.e., single parent). Finally, adolescents' average grades were evaluated to help characterize the behavioral risk factors for use of electronic cigarettes. Teens' responses were coded on a 9-point Likert-type scale ( $1=$ All/Mostly $A$ 's; $4=B / C^{\prime}$ s; $9=$ All/Mostly $F$ 's). In summary, information derived from responses on the SIF were used to create latent variables for the Genetics/Biology (i.e., parent drug dependence, sibling drug dependence), Social Environment (i.e., SES, gender, community type, and parent marital status), and Behavior (i.e., academic performance) components in the proposed model. 
Youth Risk Behavior Survey (YRBS) (Centers for Disease Control and Prevention, 2015). The YRBS is an 89-item questionnaire that assesses six types of health-risk behaviors: (1) unintentional injuries and violence, (2) use of tobacco products, (3) alcohol and other drug use, (4) risky sex behaviors, (5) diet, and (6) physical activity. Items that measure similar health behaviors (e.g., eating habits, bullying) are grouped together. There are no subscales or total scores; instead, each item is evaluated individually. Youth use a multiple-choice response format to respond to questions such as "How old were you when you smoked a whole cigarette for the first time?"

The tobacco, electronic cigarette, alcohol, and marijuana sections of the YRBS were used to form variables for the Behavior component in the proposed model. The primary outcome was adolescents' e-cig behavior, which consisted of lifetime- and current-use. Lifetime-use of electronic cigarettes was measured by asking adolescents if they had ever used an e-cig $(0=n o$, $1=y e s)$, and current e-cig use was measured by asking adolescents to indicate use during the past 30-days on a 7-point Likert-type scale ranging from 0 (0 days) to 6 (all 30 days). To obtain measures of substance use other than e-cigarettes, lifetime use of alcohol and cigarettes were included. Items assessing the frequency and age of initiation of marijuana use were available and were thought to better capture adolescent marijuana use when combined. Because the two marijuana items were on different scales, they were converted to z-scores and combined into a marijuana substance use score.

To complete the proposed model, items were added to the original YRBS to examine the association between the perceived environment and use of e-cigs. Parent and peer use of tobacco and nicotine products (i.e., cigarettes, electronic cigarettes) were measured to evaluate modeling of smoking, a composite variable created for the purposes of this study. Specifically, using the 
same format as self-reported use, adolescents indicated parental use of conventional cigarettes and e-cigs (separately) during the past 30 days on a 7-point Likert-type scale ranging from $1(0$ days) to 7 (All 30 days). Peer smoking behavior was measured by Four questions were created for this study to assess peer smoking behavior., Participants were asked how many of their 5 closest friends have (1) tried a regular cigarette, (2) smoked at least one regular cigarette per week, (3) smoked at least one regular cigarette per day, and (4) smoked multiple cigarettes per day. Teens responded to these questions on a 6-point scale ranging from 0 (None) to 5 (Five). Due to differences in response formats between parent and peer items, a summary score for modeling of smoking behavior could not be obtained by simply summing items. Therefore, a substance use social norm score was created by z-scoring four items assessing parent and peer use of conventional and electronic cigarettes ([1] parent cigarette use in the past 30 days, [2] number of peers who tried a regular cigarette, [3] parent lifetime use of e-cig, and [4] number of peers who tried an e-cig), and combining them. Higher values indicate more modeling of smoking by parents and peers. Adolescents were also asked to indicate where they obtained information about e-cigs across a total of 11 sources (magazines, TV, radio, billboards, websites, online forums, social media, peers, siblings, other family); youth could endorsed each source with "yes" $($ score $=1)$ or "no" ( summed to create a total Exposure to Advertising About E-Cigs variable that was included in the Perceived Environment latent variable.

Next, because use of flavored e-liquids could represent product characteristics that may influence perceived approval and harmfulness (e.g., Grana \& Ling, 2014), additional items were added. Adolescents were asked if they used flavored e-liquids when they first used an e-cig $(1=$ yes, 2 =no), what flavor of liquid they used when they first tried an e-cig (i.e., menthol/mint, 
fruit, dessert, spice, drink, other), and the nicotine content of the e-liquid they used (i.e., $0 \mathrm{mg}, 1$ $12 \mathrm{mg}, 13-18 \mathrm{mg}, 19-24 \mathrm{mg}, 25+\mathrm{mg}$ ). Furthermore, teens were asked their primary reason for starting use an e-cig (i.e., taste, health benefits, reduce smoking, smoking bans, quit smoking, to save money, curiosity). Descriptive statistics were provided for these variables, but they were not included in analyses.

Because the YRBS is revised biennially by the Centers for Disease Control and Prevention (CDCP), psychometric data are not available for the 2015 version. However, results from a prior study with the 2002 version suggest that items assessing substance use have adequate test-retest reliability (Brener et al., 2002). Additionally, a review by Brener, Billy, and Grady (2003) found that YRBS self-reports of substance use were related to their respective biomarkers, such as THC urinalysis and exhaled carbon monoxide, thereby supporting the validity of responses. In summary, information derived from responses on the YRBS was used to create the primary outcome variables (i.e., current and lifetime use of electronic cigarettes) as well as latent variables for the Perceived Environment (i.e., modeling of smoking, e-cig advertisement exposure) and Behavior (i.e., alcohol, tobacco, and marijuana use) constructs in the proposed model. A list of YRBS variables included in the primary analyses, and their codes, are listed in Table 1.

Smoking Expectancy Scale for Adolescents (SESA) (Hine et al., 2007). The SESA is a 43-item self-report measure that was used to assess adolescents' attitudes and beliefs regarding consequences of using electronic cigarettes. Because there are no validated measures of electronic cigarette attitudes/beliefs, the initial instructions of the SESA were modified (i.e., participants asked to consider e-cigs rather than conventional cigarettes), but no items were added or removed. Youth rated their perceived likelihood of certain outcomes if they used an 
electronic cigarette on a 10-point Likert-type scale ranging from 0 (completely unlikely) to 9 (completely likely). The measure yielded scores for eight subscales that evaluate expectancies across several domains (i.e., affect control, social benefits, boredom reduction, weight control, appearance-presentation, health costs, social costs, and addiction). Additionally, there were two second-order subscales that measure expected benefits and costs. Higher scores indicated an outcome (e.g., social benefits, health costs) is perceived as more likely to occur.

Research suggests that adolescents tend to view smoking cigarettes as leading to generally positive (e.g., social reward) or negative outcomes ( e.g., poorer health; Dalton, Sargent, Beach, Bernhardt, \& Stevens, 1999; Hine et al., 2007). Consequently, the two secondorder subscales of the SESA were used as indices for the expected costs and expected benefits variables in the Personality construct of the proposed model. Internal consistencies for the expected benefits $(\alpha=.90)$ and expected costs $(\alpha=.95)$ subscales for the current sample were good and comparable to the reliability of the original measure (Hine et al., 2007). Results from previous studies indicated that the SESA is significantly related to smoking variables (e.g., intentions to smoke, smoking behavior, and peer smoking), impulsivity, and inattention (Foster, Racicot, \& McGrath, 2012; Hine et al., 2007).

Smoking Self-Efficacy Scale (SSES) (Lawrance, 1989). The SSES was used to assess teenagers' self-efficacy to resist using electronic cigarettes. No measures of self-efficacy have been validated for use of vapor products. The instructions of this instrument were modified slightly to assess ability to resist using e-cigarettes, in particular; however, no items were added or removed. The SSES is a 36-item self-report measure that evaluates youths' perceived ability to resist using an e-cigarette across several situations. Respondents indicate how sure they are that they would be able to resist using an e-cigarette in situations such as "when you are at a friend's 
house, no adults are home" on a 6-point Likert-type scale ranging from 1 (I am very sure that I would use an e-cig) to 6 (I am very sure I would NOT use an e-cig). Consistent with the original measure, this questionnaire yielded scores for three subscales that measure ability to resist using e-cigarettes in the face of different influences: emotional (e.g., "when you feel ashamed"), friends (e.g., "when you are at a party"), and opportunity (e.g., "when you are at school during recess or after school"). For the purposes of the current study, a more general estimate of selfefficacy was desired. Therefore, the three subscales were added together to create a total selfefficacy composite score, which contributes to the Personality component of the proposed model. Higher scores indicated higher levels of self-efficacy to resist using electronic cigarettes.

Internal consistency for the total self-efficacy score in the current study was excellent $(\alpha$ $=.97$ ) and comparable to the estimates of the subscales reported in the validation study (Lawrance, 1989; $\alpha=.94-.97)$. Results from the validation study indicate that self-efficacy scores were related to smoking behavior at the time of assessment, and predicted smoking behaviors six months later. The SSES has been used throughout the adolescent smoking literature, has been related to smoking status (Kremers, Mudde, \& de Vries, 2001), and has demonstrated sensitivity to the influence of cessation interventions (Patten et al., 2008).

Brief Sensation-Seeking Scale (BSSS) (Hoyle, Stephenson, Palmgreen, Lorch, \& Donohew, 2002). The BSSS is an 8-item self-report questionnaire that was used to assess students' reports of sensation-seeking. Youth indicate how much they agree with statements such as "I would like to explore strange places" on a 5-point Likert-type scale ranging from 1 (strongly disagree) to 5 (strongly agree). Scores are averaged to yield an overall sensationseeking score as well as four subscales: (1) experience seeking, (2) boredom susceptibility, (3) thrill and adventure seeking, and (4) disinhibition. Higher scores indicated more sensation- 
seeking. For the purposes of this study, the overall sensation-seeking score was used and added to the Personality construct of the proposed model.

The overall sensation-seeking score for $B S S S$ demonstrated acceptable internal consistency for the current sample $(\alpha=.76)$. The BSSS has demonstrated convergent validity with other measures of sensation-seeking (Stephenson et al., 2003). This same study (Stephenson et al., 2003) found statistically significant associations between the BSSS and middle- and highschooler reports of tobacco, alcohol, and marijuana use.

Mini International Personality Item Pool (Mini-IPIP) (Donnellan, Oswald, Baird, \& Lucas, 2006). The Mini-IPIP is a 20-item self-report questionnaire that was used to measure personality characteristics. Youth indicate how accurately statements such as "[I] am the life of the party" describe them using a 5-point Likert-type scale ranging from 1 (very inaccurate) to 5 (very accurate). The responses across individual items were averaged to yield five subscale scores: (1) Extraversion, (2) Agreeableness, (3) Conscientiousness, (4) Neuroticism, and (5) Intellect/Imagination. Higher scores indicated greater levels of the respective personality trait. The internal consistencies of subscales taken from the current sample were: good for Extraversion $(\alpha=.82)$, acceptable for Agreeableness $(\alpha=.77)$, questionable for Conscientiousness $(\alpha=.63)$, unacceptable for Neuroticism $(\alpha=.45)$, and questionable for Intellect/Imagination $(\alpha=.61)$. The current sample's internal consistencies for the Extraversion, Agreeableness, Conscientiousness, and Intellect/Imagination subscales were comparable to the standardization sample ( $\alpha$ 's $=.81, .78, .68$, and .62, respectively; Donnellan et al., 2006). However, the internal consistency for the Neuroticism subscale in the current sample was notably worse than the standardization sample $(\alpha=.69)$. Extraversion has been associated with smoking in samples youth (Petraitis et al., 1995; Stein, Newcomb, \& Bentler, 1996). Therefore, 
the Extraversion subscale was included in the Personality latent variable of the current study's PBT model.

\section{Results}

\section{Preliminary Analyses}

Data Screening. Data were reviewed for missing values and to ensure that data were missing at random. Data from three participants were excluded due to concerns about their responses to the questionnaires, resulting in 519 participants being included in the dataset. Rates of missing data for individual variables ranged from $0 \%$ to $3.4 \%$; a total of $14.8 \%(\mathrm{n}=77)$ of the full sample had missing data on at least one of the variables used in the primary analyses. Little's MCAR test indicated that data were missing at random. Group-mean imputation was used for participants with less than $20 \%$ of items missing on a specific questionnaire. List-wise deletion was used for all other cases. A total of 21 participants were not included in analyses due to missing data that could not be imputed on one or more of the predictor or outcome variables, resulting in 498 participants with complete data. All predictor variables were entered simultaneously into a multiple linear regression to test for multicollinearity and screen for multivariate outliers. Cut-off values of Tolerance $\geq .40$ and VIF $\leq 4.0$ were used to screen for multicollinearity, and a critical value of 43.82 was used to identify multivariate outliers. Collinearity statistics indicated potential issues of multicollinearity with the SES (Tolerance $=$ $.32 ; \mathrm{VIF}=3.17)$ and Population Density (Tolerance $=.33 ; \mathrm{VIF}=3.00)$ variables. Since these variables are thought to be conceptually important, and the VIF statistic was under the cut-off, it was decided to retain them in analyses. Four cases had a Mahalanobis distance $\geq 43.82$ indicating the presence of multivariate outliers; these participants were removed from analyses. This resulted in 494 participants being included in the analyses. 
Recruitment. Over the course of the study, 1,073 adolescents were asked to participate, and a total of 522 participated, resulting in an average recruitment rate of $48.64 \%$ Recruitment rates across sites ranged from $29.03 \%$ to $76.67 \%$, with recruitment rates being highest in the adolescent medicine clinic. Across all school sites, ten participants consented to participate in the study at school sites but were absent on the day of the study, resulting in approximately $49.58 \%$ of participants consenting to the study. Only 9 students returned consent forms but indicated that they did not want to participate in the study.

Descriptives. Descriptive statistics were computed for the sample's demographic characteristics (Table 2) and the predictor variables (Tables 3-4). Participants in this study were predominantly Caucasian females in their Sophomore or Junior year of school, with an average age of approximately 16 years old, and from intact families. Predictor and outcome variables were tested for skewness and kurtosis; appropriate transformations were used for values of 2 or more. Skewness and/or kurtosis values were above the cut-off of 2 for the Marijuana Norms $($ Skew $=2.37$, Kurtosis $=5.32)$, Grades $($ Skew $=1.86$, Kurtosis $=4.83)$, and Self-Efficacy to Resist Using E-Cigs (Skew = -1.59, Kurtosis $=2.10$ ) variables. Following square transformation, skewness and kurtosis values for Marijuana Norms (Skew $=1.51$, Kurtosis $=.90)$, Grades (Skew $=1.21$, Kurtosis $=1.15)$, and Self-Efficacy $($ Skew $=1.06$, Kurtosis $=1.07)$ indicated that these variables had a normal distribution.

E-Cig Descriptives. Next, descriptive and frequency statistics were conducted for variables related to e-cig use. A total of $37.7 \%(n=186)$ teens said that they used an electronic cigarette, even one puff, at least once in their lifetime. Approximately $18 \%(\mathrm{n}=89)$ of participants said that they had used an electronic cigarette in the past 30 days. Moreover, slightly less than half $(47.85 \%)$ of teens who said they tried an e-cigarette at least once reported using an 
e-cig in the past 30-days. This suggests that almost half of teens who have used an e-cig would be considered "current users." The most commonly reported reason for trying an e-cig was curiosity $(65.22 \%, \mathrm{n}=90)$, followed by low perceived health risks $(10.9 \%, \mathrm{n}=15)$, better taste than cigarettes $(8.7 \%, \mathrm{n}=12)$, wanting to cut down on/quit smoking $(4.3 \%, \mathrm{n}=6)$, wanting to do "smoke tricks" $(4.3 \%, \mathrm{n}=6)$, because friends were using them $(1.4 \%, \mathrm{n}=2)$, wanting to reduce stress $(1.4 \%, \mathrm{n}=2)$, because they smell $\operatorname{good}(0.7 \%, \mathrm{n}=1)$ or because they are easy to hide $(0.7 \%, \mathrm{n}=1)$. An overwhelming majority $(91.7 \%, \mathrm{n}=132)$ of participants reported that they used a flavored liquid when they first tried an e-cig. The most commonly reported flavor was fruit $(67.9 \%, \mathrm{n}=89)$ followed by dessert/candy $(13.8 \%, \mathrm{n}=18)$, menthol $(6.1 \%, \mathrm{n}=8)$, spice (e.g., cinnamon; 5\%, $\mathrm{n}=7$ ), and drink (e.g., coffee, margarita; 3.1\%, $\mathrm{n}=4$ ). Seven participants $(5.3 \%)$ reported "other" as the liquid they tried, which included "Unicorn milk" $(1.4 \%, \mathrm{n}=2)$, not knowing the flavor $(1.4 \%, \mathrm{n}=2)$, and a mixture of flavors (i.e., vanilla mountain dew; $0.7 \%$, $n=1)$. The largest proportion of students $(33.6 \%, n=46)$ said that they did not know the nicotine concentration of the e-liquid that they use. The second-most common response was 0mg $(32.1 \%, \mathrm{n}=44)$, followed by $1-12 \mathrm{mg}(23.4 \%, \mathrm{n}=32), 13-18 \mathrm{mg}(6.6 \%, \mathrm{n}=9)$, or $19 \mathrm{mg}$ or more $(4.4 \%, \mathrm{n}=6)$. Most students said that they got their e-cig from a friend or classmate $(63.6 \%, \mathrm{n}=$ 82), although the second-most common source was a vape shop $(17.8 \%, \mathrm{n}=23)$.

Finally, between-group comparisons were conducted to examine differences in the independent and dependent variables between recruitment sites (suburban Ohio, suburban WV, rural WV, rural PA, and adolescent medicine clinic).

Demographics. Results indicated that there were statistically significant differences in average grades between sites, $F(4,492)=12.48, p<.001$. Specifically, students recruited from the school in suburban Ohio $(\mathrm{M}=1.30, \mathrm{SD}=.30)$ and suburban $\mathrm{WV}(\mathrm{M}=1.30, \mathrm{SD}=.34)$ 
reported higher grades than students recruited from rural WV $(\mathrm{M}=1.50, \mathrm{SD}=.42)$, rural PA $(\mathrm{M}$ $=1.65, \mathrm{SD}=.41)$, or the adolescent medicine clinic $(\mathrm{M}=1.50, \mathrm{SD}=.50)$; there was no statistically significant difference in grades between suburban Ohio and suburban WV. There was also a statistically significant difference in participant gender between sites, $X^{2}(\mathrm{df}=8)=$ $40.81, p<.001$. post-hoc analyses revealed that a large proportion of the students recruited from the adolescent medicine clinic were female $(84.4 \%)$ relative to schools in suburban Ohio $(56.9 \%)$, suburban $(60.4 \%)$ and rural WV $(50.6 \%)$, or rural PA $(46.3 \%)$.

Biology/Genetics. Results from a Pearson Chi-Square test indicated that there were not statistically significant differences forimmediate $\left(X^{2}[\mathrm{df}=4]=4.38, p=.36\right)$ or extended $\left(X^{2}[\mathrm{df}=\right.$ 4] $=1.59, p=.81$ ) family histories of substance dependence.

Substance Use. There were also statistically significant differences in cigarette $\left(X^{2}[\mathrm{df}\right.$ $=4]=61.14, p<.001)$, alcohol $\left(X^{2}[\mathrm{df}=4]=14.75, p=.01\right)$, and lifetime $\left(X^{2}[\mathrm{df}=4]=29.76, p<\right.$ $.001)$ and past-30-day $\left(X^{2}[\mathrm{df}=4]=13.38, p=.01\right)$ use of electronic cigarette use between sites. A smaller proportion of students in the suburban Ohio (11.8\%) and suburban WV (17\%) schools reported having tried a conventional cigarette relative to students recruited from the adolescent medicine clinic (40.6\%), rural WV (52.9\%) and rural PA (34.1\%). A greater percentage of students from schools in rural WV (68.2\%) and rural PA (70.7\%) reported having used alcohol relative to students in suburban WV (47.5\%). Fewer students from suburban Ohio also reported said they tried an e-cig (24.3\%) relative to students from rural WV (55.3\%), rural PA (56.1\%), and adolescent medicine (46.9\%). Similarly, fewer students from suburban WV (34\%) reported having tried an electronic cigarette relative to teens recruited from rural WV or rural PA. Finally, fewer students from suburban Ohio said that they had used an e-cig in the past 30 days (10.3\%) than students from suburban WV (19.6\%), rural WV (20\%), and rural PA (34.1\%). A smaller 
proportion of students in rural WV reported using an e-cig in the past 30 days than students from rural PA.

Perceived Environment. Results from a one-way ANOVA suggested that there was a statistically significant difference in modeling of smoking, $F(4,488)=18.2, p<.001$, but not amount of advertisement, $F(4,489)=0.72, p=.58$. Post-hoc analyses revealed that students from suburban Ohio reported lower modeling of smoking $(\mathrm{M}=-1.49, \mathrm{SD}=2.46)$ than students from suburban $(\mathrm{M}=-0.39, \mathrm{SD}=3.13)$ and rural $\mathrm{WV}(\mathrm{M}=1.67, \mathrm{SD}=3.69)$, rural $\mathrm{PA}(\mathrm{M}=1.55$, $\mathrm{SD}=4.49)$, and the adolescent medicine clinic $(\mathrm{M}=1.82, \mathrm{SD}=3.94)$. In addition, students recruited from the school in suburban WV reported lower social smoking norms that students in rural WV, rural PA, and the adolescent medicine clinic. There were no differences in smoking norms between samples recruited from rural WV, rural PA, or the adolescent medicine clinic.

Personality. Finally, a one-way ANOVA with Tukey HSD post-hoc analyses was used to examine differences in personality variables between sites. Results indicated that there were statistically significant differences in youth reports of agreeableness, $F(4,489)=5.95, p<.001$; conscientiousness, $F(4,489)=2.70, p=.03$; intellectual imagination, $F(4,489)=50.3, p=.001$; perceived costs of using an e-cig, $F(4,489)=5.19, p<.001$; and self-efficacy to resist using ecigs, $F(4,489)=2.68, p=.03$. Post-hoc analyses revealed that students recruited from the school in suburban Ohio rated themselves higher on agreeableness $(\mathrm{M}=3.97, \mathrm{SD}=.67)$ than adolescents from rural WV $(\mathrm{M}=3.48, \mathrm{SD}=.87)$. Similarly, students from the school in suburban WV $(\mathrm{M}=3.78, \mathrm{SD}=.76)$ rated themselves higher on agreeableness than students from rural WV. Students from the school in suburban WV also rated themselves higher on conscientiousness $(\mathrm{M}=3.49, \mathrm{SD}=.79)$ than participants recruited from the adolescent medicine clinic $(\mathrm{M}=3.08, \mathrm{SD}=.91)$. Participants from the school in rural $\mathrm{WV}$ also reported lower levels 
of intellectual imagination $(\mathrm{M}=3.43, \mathrm{SD}=.58)$ than students from suburban Ohio $(\mathrm{M}=3.82$, $\mathrm{SD}=.64)$ and suburban WV $(\mathrm{M}=3.71, \mathrm{SD}=.70)$. Students in suburban Ohio also reported more perceived costs from using an electronic cigarette $(\mathrm{M}=5.35, \mathrm{SD}=2.27)$ than students in suburban $(\mathrm{M}=4.52, \mathrm{SD}=2.74)$ and rural $\mathrm{WV}(\mathrm{M}=4.05, \mathrm{SD}=2.52)$, and rural $\mathrm{PA}(\mathrm{M}=3.78$, $\mathrm{SD}=2.84$ ). Finally, although the ANOVA for self-efficacy to resist using e-cigs was significant, post-hoc tests did not reveal statistically significant differences between sites.

\section{Aim 1}

Structural equation modeling was used to examine whether the model of Problem Behavior Theory outlined by Jessor (1991) accurately predicts adolescent electronic cigarette use. All analyses were conducted using Statistical Package for Social Sciences version 21 (SPSS 21) and AMoS 21 (Arbuckle, 1995). A Maximum likelihood approach was used to estimate fit and parameter coefficients for both the measurement and structural model.

Measurement Model. The measurement model was constructed based on the model outlined by Jessor (1991, Figure 3). The choice of variables loading onto latent variables was guided by Jessor's (1991) description of the domains of PBT, and the existing literature on substance use. The Genetic/Biological latent variable was made up of the immediate and extended family substance dependence variables. Population density, gender, free school lunches (i.e., SES), and whether families were intact (i.e., married to biological parent) were predicted to load onto the Social Environment latent variable. Modeling of smoking behavior (e.g., parent and peer cigarette and e-cigarette use) and exposure to e-cig advertising were thought to load onto the Perceived Environment latent variable. It was hypothesized that the Personality latent variable would be comprised of sensation-seeking, extraversion, perceived costs of e-cig use, perceived benefits of e-cig use, and self-efficacy to resist e-cigs. Finally, the average grades, 
cigarette use, marijuana use, and alcohol use were posited to comprise the Behavior construct. Considering that the constructs of PBT are thought to represent different domains of adolescents' lives, covariances were added between all latent variables. Multiple fit indices (Root Mean Square Error Approximation $[\mathrm{RMSEA}] \leq .08$, Comparative Fit Index $[\mathrm{CFI}] \geq .90, \mathrm{CMIN} / \mathrm{DF}<$ 3.0, and overall Chi-Square with $p>.01$ ) were used to evaluate model fit as they are commonly used in the literature (Kline, 2005). Variables with loadings $<.40$ onto latent variables were reexamined to determine if they should be removed to improve fit. Modification indices were also examined and the model was revised to improve fit.

The initial model (Figure 4) included all exogenous variables hypothesized to load onto the respective latent variables. Perceived costs and benefits were co-varied as these variables were subscales from the same measure and therefore hypothesized to share significant covariance. Furthermore, sensation-seeking and extraversion were co-varied as these constructs are thought to be highly correlated. Fit indices $(\mathrm{CMIN} / \mathrm{DF}=3.15, \mathrm{CFI}=.90, \mathrm{RMSEA}=.066$, $\left.X^{2}[107]=337.20, p<.001\right)$ did not support a good model fit. Closer examination of loading for specific exogenous variables indicated that gender $(B=.02)$, exposure to advertisements $(B=$ $.12)$, intact family status $(B=-.22)$ and extraversion $(B=.21)$ had loadings $<.40$ and therefore should be deleted. After removing exposure to advertisements, the smoking norms variable was divided into four variables: parent and peer use of conventional and electronic cigarettes, respectively.

The second iteration of the model (Figure 5) included all hypothesized exogenous variables (except for gender, exposure to advertisements, and extraversion). Fit indices $\left(\mathrm{CMIN} / \mathrm{DF}=4.72, \mathrm{CFI}=.87, \mathrm{RMSEA}=.09, X^{2}[93]=439.29, p<.001\right)$ again did not support a good model fit. Furthermore, the error variance for the SES error term (e5) was negative, which 
suggests an inadmissible solution for the current model. To address this, the error terms for SES (e5) and population density (e6) were constrained to be equal, as suggested by Byrne (2016). Closer examination of loadings suggested that parent conventional cigarette $(B=.36)$ and parent electronic cigarette $(B=.32)$ use had factor loadings less than .40 ; however, these variables were retained as they are thought to be conceptually important to adolescents' perceived environment. Examination of modification indices suggested the addition of covariance between the following error variances: (a) parent electronic cigarette and conventional cigarette use, (b) participant cigarette use and peer cigarette use, (c) participant cigarette use and peer electronic cigarette use, and (d) perceived costs of electronic cigarette use and peer electronic cigarette use.

The third iteration of the model (Figure 6) included all exogenous variables in the second iteration, as well as the constrained error variances (e5 and e6) and added error covariances. Fit indices suggested good model fit $\left(\mathrm{CMIN} / \mathrm{DF}=2.67, \mathrm{CFI}=.94, \mathrm{RMSEA}=.058, X^{2}[90]=\right.$ $240.29, p<.001)$. Therefore, this model was selected to use in the structural model. It should be noted that covariances between Behavior and Personality $(B=.77)$, Behavior and Perceived Environment $(B=.84)$, and Perceived Environment and Personality $(B=.73)$ were greater than .70, which suggests a significant amount of overlap between these constructs.

Structural Model. The two outcome variables, (1) Lifetime- and (2) Current- (i.e., in the past 30 days) e-cig use, were added to the measurement model to create the structural model (Figure 7). The fit indices for the structural model indicate good model fit $(\mathrm{CMIN} / \mathrm{DF}=2.87$, $\left.\mathrm{CFI}=.94, \mathrm{RMSEA}=.062, X^{2}[113]=324.45, p<.001\right)$. Examination of standardized estimates revealed that the Biology/Genetics $(B=-.13, p=.03)$, Perceived Environment $(B=.27, p=$ $.001)$, Personality $(B=.23, p<.001)$, and Behavior $(B=.45, p<.001)$ latent variables were significant predictors of lifetime cigarette use. The Personality $(B=.57, p<.001)$ and Behavior 
$(B=.29, p=.01)$ latent variables significantly predicted current electronic cigarette use. The squared multiple correlations indicate that the current model accounts for $69 \%$ and $46 \%$ of the variance for lifetime and current e-cig use, respectively.

It should be noted that the association between Biology/Genetics and lifetime e-cig use was in the opposite direction as expected; higher scores on this construct were negatively associated with lifetime e-cig use. Post-hoc tests were conducted to further explore this finding. Odds ratios obtained from chi-square analyses suggested that teens who reported an immediate family history of substance abuse were 2.61 times more likely to report using an e-cig $\left(X^{2}[1]=\right.$ $16.43, p<.001$ ), and teens who reported a history of substance abuse in their extended family were approximately 1.66 times more likely to report using an e-cig $\left(X^{2}[1]=7.40, p=.01\right)$. This suggests that, when examined alone, immediate and extended family histories of substance abuse are positively associated with lifetime use of electronic cigarettes. Reversal of the associations once more variables are added to the model suggests (1) multicollinearity or (2) the influence of a confounding variable (Pearl, 2014). However, tolerance and VIF statistics conducted during data screening did not suggest issues with multicollinearity. Therefore, exploratory analyses were conducted using chi-square analyses and logistic regressions. Variables that were significantly correlated with immediate or extended family history of substance dependence were included in analyses. The following variables were tested: (1) participant cigarette use, (2) sensation-seeking, (3) marijuana use, (4) participant grades, (5) alcohol use, (6) parent cigarette use, (7) parent e-cig use, (8) peer cigarette use, and (9) peer e-cig use.

Post-hoc analyses revealed that the association between immediate family history of substance abuse and lifetime e-cig use reversed with the addition of certain moderator variables. There was a statistically significant interaction between immediate family history of substance 
dependence and peer e-cig use predicting lifetime e-cig use (Wald $=8.37, p=.004, \mathrm{OR}=.55)$. This finding suggests that teens who endorsed an immediate family history of substance dependence and reported more peer e-cig use were less likely to report having tried an e-cig in their lifetime. There were no statistically significant interactions between immediate or extended family history of substance dependence and any of the potential moderator variables (listed above) in predicting lifetime e-cig use.

\section{$\operatorname{Aim} 2$}

The second aim of this study was to explore how individual risk factors predicted differences in electronic cigarette use among adolescents (i.e., never users, lifetime-only, and past-30 day users). To accomplish this, a binomial logistic regression and discriminant function analysis (DFA) were conducted.

Binomial Logistic Regression. A binomial logistic regression was conducted to examine how a full model of predictors classified group membership for lifetime e-cig use. The dependent variable was lifetime use of an electronic cigarette, and the referent category was never having tried an e-cig. Predictor variables were: (1) immediate family history of substance abuse, (2) participant cigarette, (3) alcohol, and (4) marijuana use, (5) SES, (6) modeling of smoking, (7) perceived costs and (8) benefits of using an e-cig, (9) self-efficacy to resist using an electronic cigarette, (10) sensation seeking, and (11) extraversion. The full model significantly predicted lifetime e-cig use in adolescents $X^{2}(11)=411.40, p<.001$. Overall, the model correctly predicted group membership in $90.5 \%$ of cases (Table 5). The model did a slightly better job at correctly categorizing never-users relative to lifetime users.

Next, parameter estimates were examined (Table 6). Adolescents were significantly more likely to report using an e-cig if they said they had used a cigarette $(p=.02, \mathrm{OR}=2.86)$ or 
alcohol $(p=.01, \mathrm{OR}=2.67)$, had a higher score on the marijuana use variable $(p<.001, \mathrm{OR}=$ $2.23)$, reported more modeling of smoking in their social network $(p<.001$, $\mathrm{OR}=1.34)$, or rated themselves higher on extraversion $(p<.001$, OR $=2.20)$. However, teens were less likely to report having tried an e-cig if they reported more perceived costs of vaping $(p=.001, \mathrm{OR}=.52)$ and greater self-efficacy to resist using e-cigs $(p<.001, \mathrm{OR}=.22)$.

Discriminant Function Analysis. A DFA was used to examine how a full a model of risk factors predicts category of electronic cigarette use. The dependent variable was a categorical variable consisting of three groups: (1) never-users, (2) lifetime only users (i.e., have tried an e-cig, but not in the past 30 days), and (3) past-30-day users. Independent variables were drawn from variables included in the model in Aim 1 and included (1) SES, (2) modeling of smoking behavior, (3) perceived costs of using an e-cig, (4) perceived benefits of using an e-cig, (5) self-efficacy to resist e-cigs, (6) sensation seeking, and (7) extraversion. Box's M was statistically significant at $p<.001$. Review of Log determinants suggested that the assumption of covariance matrices homogeneity was violated and the discriminant function should be not interpreted. A multinomial logistic regression was used instead as it does not assume homogeneity of covariances.

Multinomial Logistic Regression. The dependent variable was the categorical variable for e-cig use: (1) never-users, (2) lifetime only users, and (3) past-30-day users; the referent category was lifetime only users. The independent variables were the same as those used in the binomial logistic regression.

The full model significantly predicted levels of e-cig use in high school students, $X^{2}(22)$ $=460.72, p<.001$. Review of the classification table (Table 7) revealed that the model correctly categorized $79.5 \%$ of participants. The model was notably better at categorizing never-users 
relative to lifetime-only and past-30-day users. Indeed, the categorization of lifetime-only users was only slightly better than chance (51.5\%). Individual parameter estimates (Table 8 ) were then examined.

Relative to the life-time only group, participants were more likely to be in the never use group if they perceived more costs for using an e-cig $(p=.01, \mathrm{OR}=1.73)$ or reported higher self-efficacy to resist using an e-cig $(p<.001, \mathrm{OR}=3.74)$. Conversely, students were less likely to be in the never use group if they had used a conventional cigarette $(p=.02, \mathrm{OR}=.30)$ or alcohol $(p=.01, \mathrm{OR}=.36)$, had a higher score on the marijuana use variable $(p=.002, \mathrm{OR}=$ $.50)$, reported more smoking in their social network $(p=<.001, \mathrm{OR}=.77)$, or rated themselves higher on extraversion $(p<.001, \mathrm{OR}=.44)$. Teens in the past-30-day category also reported significantly higher scores on the marijuana use variable $(p=.04, \mathrm{OR}=1.44)$ relative to teens in the lifetime-only category. Higher perceived costs of e-cig use $(p=.02$, OR $=.59)$ and greater self-efficacy to resist using an e-cig $(p<.001, \mathrm{OR}=.51)$ were also protective factors against past-30-day use.

\section{Discussion}

This study (1) evaluated the extent to which Problem Behavior Theory (PBT) predicted adolescent electronic cigarette use, and (2) identified individual risk factors associated with different levels of e-cig use. The results support the hypothesis that the model of PBT predicts adolescent electronic cigarette use; however, not all 5 PBT constructs were significant predictors. Results also support the hypotheses of the second aim that lifetime-only users would have higher levels of risk factors relative to never users, but lower levels of risk factors relative to past-30day users. 
This study built on the existing e-cig literature by gathering information about how and why teens try vapor products, as well as what types of products they use. The prevalence of lifetime and current electronic cigarette use in this study's sample was comparable to other studies (Kann et al., 2016; Wills et al., 2016). Almost half of e-cig users in the current sample used an e-cig in the past-30-days, which is similar to prevalence rates in other recent studies (Kann et al., 2016; Wills et al., 2015). This suggests that "current use" was relatively common among high school students who used e-cigs. Therefore, teens who use e-cigs may not try them once but instead use them multiple times.

Most students (66\%) said they tried e-cigs out of curiosity rather than for health benefits (e.g., "healthier" than cigarettes, to cut down on smoking), which mirrors results from other recent studies (Bold, Kong, Cavallo, Camenga, \& Krishnan-Sarin, 2016; Measham, O’Brien, \& Turnbull, 2016; Patrick et al., 2016). This suggests that messaging about e-cigs being "healthy" or "cleaner" alternatives to cigarettes might not be salient for teens; instead, they may view vapor products as a novel and low-risk experience. Another interesting finding was that almost all participants $(91.7 \%)$ said that they tried a flavored e-liquid the first time they tried an electronic cigarette, with the most common flavors being fruit or dessert. This finding supports the thought that flavored liquids may, in fact, appeal to youth and facilitate with e-cig initiation (Etter \& Bullen, 2011). When asked about the nicotine concentration of the e-liquid they use, almost onethird of students said that they did not know. This means that many teens may not know what types of products they are using, which could influence their perceived costs and benefits of using a device. Finally, most participants said that they got their e-cig from a friend or classmate. Therefore, peers may not only model use of e-cigs but also facilitate e-cig use by sharing devices among social networks. Altogether, these findings suggest that teens are using e-cigs out of 
novelty and curiosity, which may be associated with flavored liquids. Moreover, teens may not be aware of what is in the products they are using, particularly if they do not actually own the ccig. Therefore, this may mean that health risks (e.g., exposure to chemicals, addiction) would be less fruitful targets for educational interventions. It would be important for future studies to examine whether product characteristics predict initiating e-cig use. If there is an association between these variables, it would be necessary to change public policy to address these risk factors.

Interestingly, both independent and dependent variables were found to differ between recruitment sites. Specifically, recruitment sites differed on gender, self-reported grades, substance use (i.e., alcohol, cigarettes, e-cigs), modeling of smoking, personality traits (i.e., agreeableness, conscientiousness, and intellectual imagination), and perceived costs of e-cig use. There was a difference in gender between the adolescent medicine clinic and all the school sites, which may be a product of the population that was sampled. Many more teenage females attend adolescent medicine clinics than do males, particularly because these physicians have specializations in reproductive medicine. The between-site differences observed in grades, agreeableness, conscientiousness, and intellect/imagination were small and therefore may be statistically significant due to the large sample size. However, differences in substance use, e-cig use, modeling of smoking, and perceived costs of e-cig use were large enough to suggest systematic differences between sites. Efforts were made during recruitment to recruit "typical" students (e.g., avoiding AP classes, recruiting from required classes like health and government). However, the remaining differences suggest that school-level variables are important and should be examined in the future. It is possible that the schools have different policies on substance use (e.g., consequences if caught using e-cigs), which may influence use. Student populations may 
also have different social norms and cultures surrounding e-cig use (i.e., more or less accepting), which could influence how likely teens are to use e-cigs. Moreover, the schools are located in different states that have different laws about e-cigs, which may influence access to and use of these products. Finally, schools were located in different community types (i.e., rural and suburban). Rates of substance use are significantly higher among rural teens than urban and suburban populations (Atav \& Spencer, 2002). Therefore, the differences in substance use between sites may be partially influenced by environmental variables (e.g., social norms more accepting of substance use, increased access to substances). Other studies (e.g., Mrug, Gaines, $\mathrm{Su}, \&$ Windle, 2010) have found that both school- and individual-level variables are associated with substance use, which further supports the need for closer examination. Future studies may benefit from using methodological and statistical approaches to explore how nested predictors are associated with use of electronic cigarettes. It may also be helpful to use sampling methods (e.g., stratified sampling) to recruit equal numbers of participants from each school to permit between-site comparisons.

The primary aim for this study consisted of two hypotheses: (1) the model of PBT would significantly predict lifetime and current use of electronic cigarettes, and (2) the five latent constructs of PBT would be significantly associated with lifetime and current e-cig use. The first hypothesis was supported as the full structural model demonstrated good fit; however, the second hypothesis was not supported. Only four latent constructs (biology/genetics, perceived environment, personality, and behavior) were associated with lifetime electronic cigarettes, and only the personality and behavior latent variables were associated with past-30-day use. These findings may mean that PBT is better at explaining lifetime use than past-30-day use. These results may also mean that different constructs (i.e., personality, behavior) predict different levels 
of e-cig use, which has been observed in other studies. For instance, Wills and colleagues (2015) found that adolescents' perceptions of e-cigs as healthier was a risk factor for e-cig only use, but not dual-tobacco (i.e., e-cig and conventional cigarette) use. However, the cross-sectional nature of this study precludes firm conclusions about whether certain risk factors lead to regular versus experimental use of electronic cigarettes.

Interestingly, the social environment (i.e., SES, population density) was not associated with either outcome variable. Different social environments may foster different levels of risk and protective factors (e.g., differences in peer groups, access to substances, adequate health education, perceptions of costs/benefits), which may be the primary predictor of e-cig use. Other studies (Wills et al., 2015) have found that social environment variables (e.g., gender) were not associated with e-cig use once other variables were included in models. Therefore, it may be that the differences in social environment variables result in differences in other risk factors (e.g., perceived costs/benefits) that ultimately result in e-cig use. It should be noted that some variables commonly included in the social environment (e.g., ethnicity) were not included in the current study due to small cell sizes. Therefore, it is possible that social environment construct was not fully captured in this study. Going forward, it would be helpful to utilize mediation analyses to determine if other protective and risk factors explain the association between the social environment and e-cig use. Furthermore, it would be important to include a more diverse sample to be able to test all possible social environment variables (e.g., race/ethnicity).

The second aim also had two hypotheses: teens who had used an electronic cigarette in their lifetime but not in the past 30 days ("lifetime only") would have (1) higher levels of risk factors than teens who had not used an e-cig and (2) lower levels of risk factors than their peers in the past-30-day e-cigarette use group. The results from binomial and multinomial logistic 
regressions supported both hypotheses. It should be noted that the model for the multinomial logistic regression was better at categorizing never users relative to lifetime-only and past-30-day users; however, the binomial logistic regression did an adequate job differentiating between teens who had and had not used an e-cig. Lifetime-only users may have more moderate level of risk factors, which could make it difficult to distinguish them from never and past-30-day users. Furthermore, there may be certain variables that help differentiate between moderate levels of risk that were not included in the current model. Finally, when comparing teens who have and have not used an e-cig, there appear to be specific risk factors that can be utilized for future studies on screening and can potentially influence the development of prevention and intervention efforts.

Results from the binomial logistic regression identified substance use (cigarettes, alcohol, and marijuana), modeling of smoking, and extraversion as statistically significant risk factors for lifetime e-cig use, while perceived costs of using an e-cig and self-efficacy to resist e-cig use were protective factors. Similarly, results from the multinomial logistic regression identified substance use, modeling of smoking, and extraversion as risk factors for lifetime only e-cig users versus never users; perceived costs and smoking resistance self-efficacy were protective factors. Marijuana use was the only significant risk factors for past-30-day use relative to lifetime only use, while perceived costs and resistance self-efficacy were protective factors. Overall, substance use and personality variables were the most reliable predictors of levels of e-cig use, which is consistent with results from other studies (Carroll Chapman \& Wu, 2014; Goniewicz \& Zielinska-Danch, 2012; Wills et al., 2015). Notably, conventional cigarette and alcohol use did not differentiate between lifetime only and past-30-day users. Therefore, using e-cigs more regularly may represent a progression to risky substance use (e.g., using illicit drugs). These 
findings also suggest that youth who use one substance should be screened for use of other substances. In addition, teens who report that they observe their parents and peers using conventional or electronic cigarettes should be screened for substance use and would be ideal targets for prevention efforts. Moreover, the strong and reliable associations between different substance use variables suggests that it would be advantageous to use interventions that target overall substance use rather than focusing exclusively on alcohol, tobacco, etc. It would also be interesting for future studies to explore whether targeted interventions for one health-risk behavior result in decreases in associated health-risk behaviors.

One unique finding in this study was that self-efficacy to resist e-cigs and perceived costs were protective factors against lifetime and past-30-day use of electronic cigarettes. The finding that higher perceived costs were associated with less e-cig use is congruent with much of the adolescent and adult e-cig literature (Anand et al., 2015; Pepper, Emery, Ribisl, Rini, \& Brewer, 2015; Roditis \& Halpern-Felsher, 2015; Wills et al., 2015). Interestingly, perceived benefits were not a risk factor for e-cig use. Therefore, adolescents appear to be more likely to use an e-cig because they view a low likelihood of adverse consequences rather than personal gains. Based on these findings, perceived costs and self-efficacy to resist e-cigs represent fruitful areas for intervention and prevention efforts. A recent study (Kong, Cavallo, Camenga, Morean, \& Krishnan-Sarin, 2016) explored preferred message framing for e-cig prevention efforts. It would be pertinent to build on this budding literature by identifying what specific costs (e.g., social, health, addiction risk) are most strongly associated with e-cig use and tailoring interventions efforts based on the recommendations by Kong and colleagues (2016).

When interpreting the finding from this study some limitations should be considered. First, lower recruitment rate may have increased the risk of a selection bias. Overall, 
approximately $50 \%$ of youth approached participated, and the rates of participation varied significantly between sites (i.e., 29\% - 77\%). The overall recruitment rate for the current study was comparable to what has been reported in other studies in which high school students were recruited from school settings (Chartier et al., 2008) or for studies about substance use (Rait, Prochaska, \& Rubinstein, 2015). Students may have not participated for many reasons. First, they may have not participated because they did not feel comfortable answering questions about substance use. This suggests a possible selection bias; however, overall rates of substance use were comparable to other studies (e.g., Kann et al., 2016), so any bias in the current study was likely present elsewhere. Also, a social desirability bias may have occurred for those who participated, likely resulting in teens underreporting e-cig use. Nonetheless, the results of the current study are more likely a conservative estimate of associations between variables.

The recruitment and consent procedures used may have also negatively impacted recruitment rates. A study by Chartier and colleagues (2008) found that using active consent procedures (i.e., requiring a parent's written consent to participate) resulted in a statistically significant decrease in participation rates relative to passive procedures (i.e., requiring parents to only sign if they did not want their child to be in the study). Moreover, active consent procedures have resulted in the exclusion of high risk groups (Frissell et al., 2004). Therefore, the use of active consent procedures likely played a role in the observed recruitment rates and may have increased the risk of selection bias. Interestingly, recruitment rates were highest for the adolescent medicine clinic (76.67\%) where patients completed consent forms and questionnaire on the same day. Future studies would benefit from using procedures that allow students to complete consent forms on the same day (i.e., face-to-face recruitment) or use passive consent 
procedures. These methodologies would hopefully increase overall participation and include more "high-risk" students.

Given that most other studies (Wills et al., 2015; 2016) utilize similar consent protocols and would be affected the same way, it is likely safe to assume that the current findings can be compared with these studies. In addition, because a lower-risk sample was likely collected, the bias may be towards, rather than away from, the null hypothesis. Therefore, results in the current study may be a more conservative estimate of findings. However, to fully understand all risk factors and develop effective interventions, it is important for future projects to purposely sample from high and low risk populations.

In addition to differences in recruitment rates between sites, different types of participants may have been recruited from each site, which may contribute to the observed between-site difference and differential rates of participation. Specifically, teens recruited from suburban schools may be higher functioning (e.g., better grades, engage in less risky behaviors) while rural teens may have overall lower levels of functioning. Indeed, between-site differences reported in the results section support that adolescents from sites differed on multiple measures of psychosocial variables (e.g., grades, self-efficacy to resist using e-cigs) and health-related (e.g., substance use).

The inclusion of teens from the adolescent medicine clinic also represents a potential limitation that should be considered. Although teens were recruited from the clinic in an effort to expand the sample with regard to diversity and risk factors, these participants may be systematically different than youth recruited from high school classrooms. For instance, if they visit their physician more frequently, they may know more about the potential health-risks of electronic cigarettes. Future studies may wish to use sampling methods that control for school- 
and community-level differences (e.g., stratified sampling) that can impact substance use. Furthermore, statistical approaches such as hierarchical linear modeling should be employed to explore the ways in which school-level variables are associated with adolescent e-cig use.

A second limitation of the current study is that the nature of questions being asked may increase the risk of a social desirability bias. Laws prohibit the use of electronic cigarettes, conventional cigarettes, and alcohol for individuals under a certain age, and state that any marijuana use is illegal. Therefore, teens may under-report substance use. Moreover, teens may respond differently to questions about perceived costs/benefits of e-cig use and self-efficacy to resist using an e-cig to try to portray themselves as less approving of vapor products and less likely to try one. Efforts were made to ensure confidentiality and convey to participants that responses will not be shared with parents or teachers, which can help decrease a social desirability bias. A review of studies found that teen-reports of substance use were closer to estimates from biomarkers when there was more perceived confidentiality (Brener, Billy, \& Grady, 2003). Therefore, it is possible that social desirability bias may have been less prevalent in the current study. Furthermore, rates of substance use were similar to what is reported in other studies (e.g., Kann et al., 2016), which again suggests that any bias is likely shared by other studies. In the future, it would be helpful to include measures of social desirability in the questionnaire packets. This would allow researchers to estimate the potential impact of subject roles on predictor and outcome variables.

Third, the study is cross-sectional in nature, which precludes making causal inferences. The results demonstrate associations between e-cig use and risk (i.e., substance use) and protective factors (perceived costs, e-cig-resistance self-efficacy). This could mean that teens with lower perceived costs of e-cigs may be more likely to try one. However, it is also possible 
that teens who try an e-cig later report that e-cigs have less costs. Thus far, only one longitudinal study about risk factors predicting e-cig in adolescents exists (Wills et al., 2016). It is imperative that more longitudinal studies about risk factors and e-cig initiation be conducted. Results from these studies can help identify risk factors of first trying vapor products, characterize trajectories of substance use, and guide the development and implementation of public policy and prevention efforts.

Another potential limitation of this study is the way in which the biological and genetics latent variable was measured. PBT suggests that family history of substance addiction would likely be a part of this construct. However, due to methodological and logistical constraints, it was not possible to obtain parent-reports of addiction and thus youth-reports were used. It is possible that youth-reports of substance addiction in their immediate family may not be accurate, particularly if it is something not discussed or openly apparent in the family. This circumstance could impact the validity of these reports and therefore the utility of the biology/genetics latent variable. Future studies should attempt to incorporate parent-reports of addiction to overcome this barrier.

The way in which substance use (i.e., cigarettes, alcohol, marijuana) and e-cig use were measured also represents a potential limitation. These variables were categorical measures in which participants reported whether they had used the particular substance (i.e., yes/no) and how frequently they had used these substance in the past 30 (cigarette, e-cig, alcohol) or 100 (marijuana) days. Having participants report use categorically limits some of the variability in responses and makes it difficult to determine how different levels of substance use relate to levels of e-cig use. Moreover, the use of categorical variables limits the examination of differences between levels of substance use. 
Finally, the sample obtained was predominantly Caucasian, from suburban and rural communities, academically successful, and from intact families. This suggests that the current sample may have better overall functioning and exposure to fewer risk factors relative to the national population. This could limit generalizability of findings, which could also hamper the development of prevention interventions that can be efficacious at a national level. To avoid this, future studies should utilize methodologies that yield a more representative sample.

Despite the limitations, the current study has many strengths. First, this study applied PBT (Jessor, 1991), an empirically tested theoretical model of adolescent risk behaviors, to explain electronic cigarette use. Few studies in the electronic cigarette literature (i.e., Wills et al., 2015) were based in theory. Therefore, most studies did not build on the results of other substance use literatures, which could result in the omission of important predictors. This study also utilized two advanced, multivariate statistical approaches (structural equation modeling and logistic regression) to test hypotheses. These methodologies combated the use of repeated univariate tests, which could inflate the risk of committing a type I error. Furthermore, multivariate approaches permit the modeling and examination of more complex relationships amongst multiple independent and dependent variables. Finally, standardized measures (i.e., SESA, BSSS, SSES, MINI-IPIP) were used in the current study, which helped preserve experimental validity. Some previous studies (e.g., Cho, Shin, \& Moon, 2011; Pepper \& Brewer, 2013; Wills et al., 2015; 2016) did not use standardized measures to assess variables of interest, which can limit the accuracy of the conclusions that are drawn.

In conclusion, this study built on the current knowledge about risk factors for electronic cigarette use in adolescents. The results of this study suggest that PBT may be able to explain electronic cigarette use, although not all domains of risk factors were statistically significant 
predictors. Specifically, biology/genetic, perceived environment, behavioral and personality risk factors were associated with lifetime electronic cigarette use; only the behavioral and perceived environment domains were associated with current e-cig use. Furthermore, individual predictors differentiated between levels of electronic cigarette use. Higher levels of substance use, modeling of smoking, and extraversion were risk factors for lifetime e-cig use, while perceived costs, SES, and self-efficacy to resist using an e-cig were protective factors. High levels of marijuana use and modeling of smoking were also risk factors for past-30-day e-cig use, relative to lifetime only use; perceived costs and self-efficacy to resist using an e-cig were again protective factors. Results from this study can be used to improve screening for risk of using electronic cigarettes in multiple settings (e.g., schools, medical and mental clinics), as well as aid in the development of public policy and prevention efforts.

\section{Dissemination}

To ensure results from this study will be utilized by key stakeholders, a plan to disseminate results at multiple levels was developed. It is vitally important that results of this study reach the scientific and medical communities to encourage additional research and application of findings in clinical settings. The primary method of disseminating results will be through presentations at academic conferences and publishing manuscripts in scientific journals. Currently, two posters have been presented at the Society for Pediatric Psychology Annual Conference, which is a gathering of researchers and clinicians interested in understanding the psychosocial correlates of health behaviors in youth. Therefore, the results of this study are thought to be highly relevant to this group. Moreover, many of these psychologists work in multidisciplinary medical settings (i.e., specialty clinics, primary care) and can help educate 
other healthcare providers. Preliminary results were also disseminated directly to local healthcare providers through a presentation at the WVU Department of Pediatrics Grand Rounds.

Findings from this study are also relevant for educational professionals. Moreover, collaboration and education of health teachers will allow them to rapidly provide evidence-based lessons to their students, who are also one of the largest at-risk groups. Dissemination of results to schools began with in-class presentations by research team members in local WV schools. Teachers and school administrators will also receive brief executive summaries of e-cig use in their schools. These summaries will outline prevalence of e-cig use, demographic differences in e-cig use, and risk factors for e-cig use. This will allow schools to (1) identify students at-risk for e-cig use and (2) provide educational interventions that capitalize upon known risk and protective factors.

Lastly, this study has the opportunity to impact state-level organizations that can reduce use of electronic cigarettes by adolescents. Specifically, it may be important to limit access to devices and e-liquids, fund research on electronic cigarette use, and encourage education about electronic cigarette use. To reach state-level stakeholders, executive summaries of the current study will be created and sent to the West Virginia Division of Tobacco Prevention and the members of the Health and Human Resources Committee in the WV House of Representatives and State Senate. 


\section{References}

Ajzen, I. (1985). From decisions to actions: A theory of planned behavior. In J. Kuhl. \& J. Beckmann (Eds.), Action-control: From cognition to behavior (pp. 11-39). New York: Springer.

Ajzen, I. (1988). Attitudes, personality, and behavior. Homewood IL: Dorsey Press.

Akers, R. L., Krohn, M. D., Lanza-Kaduce, L., \& Radosevich, M. (1979). Social learning and deviant behavior: A specific test of a general theory. American Sociological Review, 636-655.

Albuquerque, E. X., Pereira, E. F., Alkondon, M., \& Rogers, S. W. (2009). Mammalian nicotinic acetylcholine receptors: from structure to function. Physiological Reviews, 89(1), 73-120.

Ambrose, B. K., Rostron, B. L., Johnson, S. E., Portnoy, D. B., Apelberg, B. J., Kaufman, A. R., \& Choiniere, C. J. (2014). Perceptions of the relative harm of cigarettes and e-cigarettes among US youth. American journal of preventive medicine, 47(2), S53-S60.

American Association of Poison Control Center (2015, April 15). E-Cigarette Devices and Liquid Nicotine. Retrieved from http://www.aapcc.org/alerts/e-cigarettes/.

Anand, V., McGinty, K. L., O’Brien, K., Guenthner, G., Hahn, E., \& Martin, C. A. (2015). Ecigarette use and beliefs among urban public high school students in North Carolina. Journal of Adolescent Health, 57(1), 46-51. http://doi.org/10.1016/j.jadohealth.2015.03.018

Arbuckle, J. (1995). AMOS: Analysis of moment structures user's guide. Small Waters, Chicago. 
Atav, S., \& Spencer, G. A. (2002). Health risk behaviors among adolescents attending rural, suburban, and urban schools: a comparative study. Family \& Community Health, 25(2), $53-64$.

Bailey, S. L., \& Hubbard, R. L. (1990). Developmental variation in the context of marijuana initiation among adolescents. Journal of Health and Social Behavior, 31(1), 58-70. http://doi.org/10.2307/2137045

Bandura, A. (1977). Self-efficacy: Toward a unifying theory of behavior change. Psychological Review, 84, 191-215.

Bandura, A. (1986). Social foundations of thought and action. Englewood Cliffs, NJ, 1986.

Bandura, A. (1982). Self-efficacy mechanism in human agency. American Psychologist, 37, 122147.

Bahl, V., Lin, S., Xu, N., Davis, B., Wang, Y. H., \& Talbot, P. (2012). Comparison of electronic cigarette refill fluid cytotoxicity using embryonic and adult models. Reproductive Toxicology, 34(4), 529-537.

Fernández, E., Ballbè, M., Sureda, X., Fu, M., Saltó, E., \& Martínez-Sánchez, J. M. (2015). Particulate Matter from Electronic Cigarettes and Conventional Cigarettes: a Systematic Review and Observational Study. Current Environmental Health Reports, 2(4), 423-429. https://doi.org/10.1007/s40572-015-0072-x

Bean, M. K., Mitchell, K. S., Speizer, I. S., Wilson, D. B., Smith, B. N., \& Fries, E. A. (2008). Rural adolescent attitudes toward smoking and weight loss: relationship to smoking status. Nicotine \& Tobacco Research, 10(2), 279-286. doi:10.1080/14622200701824968 
Behar, R. Z., Davis, B., Wang, Y., Bahl, V., Lin, S., \& Talbot, P. (2014). Identification of toxicants in cinnamon-flavored electronic cigarette refill fluids. Toxicology in Vitro, 28(2), 198-208. doi:10.1016/j.tiv.2013.10.006

Bell, K., \& Keane, H. (2012). Nicotine control: E-cigarettes, smoking and addiction. International Journal of Drug Policy, 23(3), 242-247. doi:10.1016/j.drugpo.2012.01.006

Berkowitz, A. D., \& Perkins, H. W. (1986). Problem drinking among college students: A review of recent research. Journal of American College Health, 35(1), 21-28.

Bhatnagar, A., Whitsel, L. P., Ribisl, K. M., Bullen, C., Chaloupka, F., Piano, M. R., ... Benowitz, N. (2014). Electronic Cigarettes: A Policy Statement From the American Heart Association. Circulation, 130, 1418-1436. doi:10.1161/CIR.0000000000000107

Block, J., Block, J. H., \& Keyes, S. (1988). Longitudinally foretelling drug usage in adolescence: Early childhood personality and environmental precursors. Child development, 336-355.

Bold, K. W., Kong, G., Cavallo, D. A., Camenga, D. R., \& Krishnan-Sarin, S. (2016). Reasons for Trying E-cigarettes and Risk of Continued Use. Pediatrics, 39(1), 338-40. http://doi.org/10.1542/peds.2016-0895

Botvin, G. J., Malgady, R. G., Griffin, K. W., Scheier, L. M., \& Epstein, J. a. (1998). Alcohol and marijuana use among rural youth: interaction of social and intrapersonal influences. Addictive Behaviors, 23(3), 379-387.

Brener, N. D., Billy, J. O. G., \& Grady, W. R. (2003). Assessment of factors affecting the validity of self-reported health-risk behavior among adolescents: Evidence from the scientific literature. Journal of Adolescent Health, 33, 436-457. 
http://doi.org/10.1016/S1054-139X(03)00052-1

Brener, N. D., Kann, L., McManus, T., Kinchen, S. A., Sundberg, E. C., \& Ross, J. G. (2002). Reliability of the 1999 youth risk behavior survey questionnaire. Journal of Adolescent Health, 31(4), 336-342.

Brener, N. D., McManus, T., Galuska, D. A., Lowry, R., \& Wechsler, H. (2003). Reliability and validity of self-reported height and weight among high school students. Journal of Adolescent Health, 32(4), 281-287.

Brown, C. J., \& Cheng, J. M. (2014). Electronic cigarettes: product characterisation and design considerations. Tobacco Control, 23 Suppl 2(October 2013), ii4-10. doi:10.1136/tobaccocontrol-2013-051476

Byrne, B. M. (2016). Structural equation modeling with AMOS: Basic concepts, applications, and programming. Routledge.

Camenga, D. R., Delmerico, J., Kong, G., Cavallo, D., Hyland, A., Cummings, K. M., \& Krishnan-Sarin, S. (2014). Trends in use of electronic nicotine delivery systems by adolescents. Addictive Behaviors, 39(1), 338-340. doi:10.1016/j.addbeh.2013.09.014

Cameron, J. M., Howell, D. N., White, J. R., Andrenyak, D. M., Layton, M. E., \& Roll, J. M. (2014). Variable and potentially fatal amounts of nicotine in e-cigarette nicotine solutions. Tobacco Control, 23(1), 77-78.

Carroll-Chapman, S. L., \& Wu, L. (2014). E-cigarette prevalence and correlates of use among adolescents versus adults: A review and comparison. Journal of Psychiatric Research, 54(1), 45-54. doi:10.1016/j.jpsychires.2014.03.005 
Cataldo, J. K., Petersen, A. B., Hunter, M., Wang, J., \& Sheon, N. (2015). E-cigarette marketing and older smokers: road to renormalization. American Journal of Health Behavior, 39(3), 361-371.

Centers for Disease Control and Prevention (1994). Preventing tobacco use among young people: A report of the surgeon general (Executive Summary). Morbidity and Mortality Weekly Report, 43(4), 1-24.

Centers for Disease Control and Prevention (2010). Cigarette use among high school students United states, 1991-2009. Morbidity and Mortality Weekly Report, 59(26), 797-801.

Centers for Disease Control and Prevention. (2013). Notes from the field. Morbitidy and Mortality Weekly Report, 62(35), 729-730. doi:10.2105/AJPH.77.9.1227

Centers for Disease Control and Prevention (2015) Youth Risk Behavior Survey. Available at: www.cdc.gov/yrbs. Accessed on March 26, 2015.

Cervellati, F., Muresan, X. M., Sticozzi, C., Gambari, R., Montagner, G., Forman, H. J., ... \& Valacchi, G. (2014). Comparative effects between electronic and cigarette smoke in human keratinocytes and epithelial lung cells. Toxicology in Vitro, 28(5), 999-1005.

Chaffee, B. W., Gansky, S. A., Halpern-Felsher, B., Couch, E. T., Essex, G., \& Walsh, M. M. (2015). Conditional risk assessment of adolescents' electronic cigarette perceptions. American Journal of Health Behavior, 39(3), 421-432.

Chartier, M., Stoep, A. Vander, McCauley, E., Herting, J. R., Tracy, M., \& Lymp, J. (2008). Passive versus active parental permission: implications for the ability of school-based depression screening to reach youth at risk. The Journal of School Health, 78(3), 157-64-6. 
http://doi.org/10.1111/j.1746-1561.2007.00278.x

Chen, I. L. (2013). FDA summary of adverse events on electronic cigarettes. Nicotine and Tobacco Research, 15(2), 615-616. http://doi.org/10.1093/ntr/nts145

Cho, J. H., Shin, E., \& Moon, S. S. (2011). Electronic-cigarette smoking experience among adolescents. Journal of Adolescent Health, 49(5), 542-546. doi:10.1016/j.jadohealth.2011.08.001

Croll, J., Neumark-Sztainer, D., Story, M., \& Ireland, M. (2002). Prevalence and risk and protective factors related to disordered eating behaviors among adolescents: relationship to gender and ethnicity. Journal of Adolescent Health, 31(2), 166-175.

Dalton, M. A., Sargent, J. D., Beach, M. L., Bernhardt, A. M., \& Stevens, M. (1999). Positive and negative outcome expectations of smoking: implications for prevention. Preventive Medicine, 29(6 Pt 1), 460-465. http://doi.org/10.1006/pmed.1999.0582

Dautzenberg, B., Birkui, P., Noël, M., Dorsett, J., Osman, M., \& Dautzenberg, M. D. (2013). ECigarette: a new tobacco product for schoolchildren in Paris. Open Journal of Respiratory Diseases, 3(01), 21.

De Vries, H., Dijkstra, M., \& Kuhlman, P. (1988). Self-efficacy: The third factor besides attitude and subjective norm as a predictor of behavioural intentions. Health Education Research, 3(3), 273-282. Retrieved from http://www.ncbi.nlm.nih.gov/pubmed/8822306

Donnellan, M. B., Oswald, F. L., Baird, B. M., \& Lucas, R. E. (2006). The Mini-IPIP Scales: Tiny-yet-effective measures of the Big Five Factors of Personality. Psychological Assessment, 18(2), 192-203. https://doi.org/10.1037/1040-3590.18.2.192 
Donovan, J. E. (2004). Adolescent alcohol initiation: A review of psychosocial risk factors. Journal of Adolescent Health, 35, 7-18. doi:10.1016/j.jadohealth.2004.02.003

Duke, J. C., Lee, Y. O., Kim, A. E., Watson, K. a, Arnold, K. Y., Nonnemaker, J. M., ... Lee, Y. O. (2014). Exposure to electronic cigarette television advertisements among youth and young adults. Pediatrics, 134(1), e29-36. doi:10.1542/peds.2014-0269

Durmowicz, E. L. (2014). The impact of electronic cigarettes on the paediatric population. Tobacco Control, 23 Suppl 2, ii41-ii46. doi:10.1136/tobaccocontrol-2013-051468

Elkins, I. J., McGue, M., \& Iacono, W. G. (2007). Prospective effects of attentiondeficit/hyperactivity disorder, conduct disorder, and sex on adolescent substance use and abuse. Archives of General Psychiatry, 64(10), 1145-1152. http://doi.org/10.1001/archpsyc.64.10.1145

England, L. J., Bunnell, R. E., Pechacek, T. F., Tong, V. T., \& Mcafee, T. A. (2015). Nicotine and the Developing Human. American Journal of Preventive Medicine, 1-8. http://doi.org/10.1016/j.amepre.2015.01.015

Epstein, J. A., Botvin, G. J., \& Spoth, R. (2003). Predicting smoking among rural adolescents: social and cognitive processes. Nicotine \& Tobacco Research, 5(4), 485-491. http://doi.org/10.1080/1462220031000118577

Etter, J. F., \& Bullen, C. (2011). Electronic cigarette: users profile, utilization, satisfaction and perceived efficacy. Addiction, 106(11), 2017-2028. 
Fairchild, A. L., Bayer, R., \& Colgrove, J. (2014). The renormalization of smoking? E-Cigarettes and the Tobacco "Endgame." New England Journal of Medicine, 370(4), 293-295. doi:10.1056/NEJMp1415160

Farsalinos, K. E., Spyrou, A., Tsimopoulou, K., Stefopoulos, C., Romagna, G., \& Voudris, V. (2014). Nicotine absorption from electronic cigarette use: comparison between first and new-generation devices. Sci Rep, 4, 4133. doi:10.1038/srep04133

Farsalinos, K. E., Romagna, G., Tsiapras, D., Kyrzopoulos, S., Spyrou, A., \& Voudris, V. (2013). Impact of flavour variability on electronic cigarette use experience: An internet survey. International Journal of Environmental Research and Public Health, 10, 72727282. doi:10.3390/ijerph10127272

Fisher, L. A., \& Bauman, K. E. (1988). Influence and selection in the friend-adolescent relationship: Findings from studies of adolescent smoking and drinking. Journal of Applied Social Psychology, 18(4), 289-314.

Flay, B. R., Hu, F. B., Siddiqui, O., Day, L. E., Hedeker, D., Petraitis, J., ... Sussman, S. (1994). Differential influence of parental smoking and friends' smoking on adolescent initiation and escalation of smoking. Journal of Health and Social Behavior, 35(3), 248-265. http://doi.org/10.2307/2137279

Frissell, K. C., McCarthy, D. M., D’Amico, E. J., Metrik, J., Ellingstad, T. P., \& Brown, S. a. (2004). Impact of consent procedures on reported levels of adolescent alcohol use. Psychology of Addictive Behaviors : Journal of the Society of Psychologists in Addictive Behaviors, 18(4), 307-15. http://doi.org/10.1037/0893-164X.18.4.307 
Foster, I., Racicot, S., \& McGrath, J. J. (2012). Attention-deficit/hyperactivity disorder subtype differentially predicts smoking expectancies in adolescents. Journal of Adolescent Health, 51(4), 393-399.

Goniewicz, M. L., Kuma, T., Gawron, M., Knysak, J., \& Kosmider, L. (2013). Nicotine levels in electronic cigarettes. Nicotine and Tobacco Research, 15(1), 158-166. http://doi.org/10.1093/ntr/nts103

Goniewicz, M. L., Knysak, J., Gawron, M., Kosmider, L., Sobczak, A., Kurek, J., ... Benowitz, N. (2014). Levels of selected carcinogens and toxicants in vapour from electronic cigarettes. Tobacco Control, 23(2), 133-9. doi:10.1136/tobaccocontrol-2012-050859

Goniewicz, M. L., \& Zielinska-Danch, W. (2012). Electronic cigarette use among teenagers and young adults in Poland. Pediatrics, 130(4), e879-e885. doi:10.1542/peds.2011-3448

Grana, R. A., \& Ling, P. M. (2014). "Smoking revolution": A content analysis of electronic cigarette retail websites. American Journal of Preventive Medicine, 46(4), 395-403. doi:10.1016/j.amepre.2013.12.010

Grana, R. A., Benowitz, N., \& Glantz, S. A. (2014). E-cigarettes: A scientific review. Circulation, 129(19), 1972-1986. doi:10.1161/CIRCULATIONAHA.114.007667

Guo, Q., Johnson, C. A., Unger, J. B., Lee, L., Xie, B., Chou, C. P., ... Pentz, M. (2007). Utility of the theory of reasoned action and theory of planned behavior for predicting Chinese adolescent smoking. Addictive Behaviors, 32, 1066-1081.

doi:10.1016/j.addbeh.2006.07.015 
Harrell, J. S., Bangdiwala, S. I., Deng, S., Webb, J. P., \& Bradley, C. (1998). Smoking initiation in youth. Journal of Adolescent Health, 23(6), 271-279. doi:10.1016/S1054139X(98)00078-0

Harrell, P. T., Marquinez, N. S., Correa, J. B., Meltzer, L. R., Unrod, M., Sutton, S. K., ... Brandon, T. H. (2014). Expectancies for cigarettes, e-cigarettes, and nicotine replacement therapies among e-cigarette users (aka vapers). Nicotine \& Tobacco Research, 17(2), 193-200. doi:10.1093/ntr/ntu149

Harrell, P. T., Simmons, V. N., Correa, J. B., Padhya, T. A., \& Brandon, T. H. (2014). Electronic Nicotine Delivery Systems ("E-cigarettes"): Review of safety and smoking cessation efficacy. Otolaryngology -- Head and Neck Surgery. doi:10.1177/0194599814536847

Hawkins, D. J., Catalano, R. F and Miller, J. Y. (1992). Risk and protective factors for alcohol and other drug problems in adolescence and early adulthood: Implications for substance abuse prevention. Psychological Bulletin, 112(1), 64-105. doi:0332909/92

Hine, D. W., Honan, C. A., Marks, A. D. G., \& Brettschneider, K. (2007). Development and validation of the Smoking Expectancy Scale for Adolescents. Psychological Assessment, 19(3), 347-355. http://doi.org/10.1037/1040-3590.19.3.347

Hoyle, R. H., Stephenson, M. T., Palmgreen, P., Lorch, E. P., \& Donohew, R. L. (2002). Reliability and validity of a brief measure of sensation seeking. Personality and Individual Differences, 32(3), 401-414. https://doi.org/10.1016/S0191-8869(01)00032-0

Jessor, R., \& Jessor, S. L. (1977). Problem behavior and psychosocial development: A longitudinal study of youth. New York: Academic Press. 
Jessor, R. (1991). Risk behavior in adolescence: A psychosocial framework for understanding and action. Journal of Adolescent Health, 12, pp. 597-605. doi:10.1016/1054139X(91)90007-K

Kann, L., McManus, T., Harris, W. A., Shanklin, S. L., Flint, K. H., Hawkins, J., ... Zaza, S. (2016). Youth Risk Behavior Surveillance - United States, 2015. Morbidity and Mortality Weekly Report. Surveillance Summaries (Washington, D.C. : 2002), 65(6), 1-174. http://doi.org/10.15585/mmwr.ss6506a1

Kandel, D. B., Kessler, R. C., \& Margulies, R. Z. (1978). Antecedents of adolescent initiation into stages of drug use: A developmental analysis. Journal of Youth and Adolescence, $7(1), 13-40$.

Kaplan, H. B., Martin, S. S., \& Robbins, C. (1982). Application of a general theory of deviant behavior: Self-derogation and adolescent drug use. Journal of Health and Social Behavior, 274-294.

Kendler, K. S., Sundquist, K., Ohlsson, H., Palmer, K., Maes, H., Winkleby, M. A., \& Sundquist, J. (2012). Genetic and familial environmental influences on the risk for drug abuse: A national Swedish adoption study. Archives of General Psychiatry, 69(7), 690-697. doi:10.1001/archgenpsychiatry.2011.2112

Kim, H. J., \& Shin, H. S. (2013). Determination of tobacco-specific nitrosamines in replacement liquids of electronic cigarettes by liquid chromatography-tandem mass spectrometry. Journal of Chromatography A, 1291, 48-55.

Kline, R. B. (2005), Principles and Practice of Structural Equation Modeling (2nd Edition ed.). New York: The Guilford Press 
Kong, G., Cavallo, D. A., Camenga, D. R., Morean, M. E., \& Krishnan-Sarin, S. (2016).

Preference for gain- or loss-framed electronic cigarette prevention messages. Addictive Behaviors, 62, 108-113. https://doi.org/10.1016/j.addbeh.2016.06.015

Kosmider, L., Sobczak, A., Fik, M., Knysak, J., Zaciera, M., Kurek, J., Goniewicz, M. L. (2014). Carbonyl compounds in electronic cigarette vapors: Effects of nicotine solvent and battery output voltage. Nicotine and Tobacco Research, 15(10). 1319-1326.

Kremers, S. P., Mudde, A. N., \& de Vries, H. (2001). "Kicking the initiation”: do adolescent exsmokers differ from other groups within the initiation continuum? Preventive Medicine, 33, 392-401. doi:10.1006/pmed.2001.0904

Kumpfer, K. L., \& Turner, C. W. (1990). The social ecology model of adolescent substance abuse: Implications for prevention. Substance Use \& Misuse, 25(S4), 435-463.

Lambert, N. M., \& Hartsough, C. S. (1998). Prospective study of tobacco smoking and substance dependencies among samples of ADHD and non-ADHD participants. Journal of Learning Disabilities, 31(6), 533-544.

Lammers, C., Ireland, M., Resnick, M., \& Blum, R. (2000). Influences on adolescents' decision to postpone onset of sexual intercourse: A survival analysis of virginity among youths aged 13 to 18 years. Journal of Adolescent Health, 26(1), 42-48.

Lawrance, L. (1989). Validation of a self-efficacy scale to predict adolescent smoking. Health Education Research, 4(3), 351-360. Retrieved from http://www.ncbi.nlm.nih.gov/pubmed/8822306 
Lee, S., Grana, R. A., \& Glantz, S. A. (2014). Electronic cigarette use among Korean adolescents: A cross-sectional study of market penetration, dual use, and relationship to quit attempts and former smoking. Journal of Adolescent Health, 54(6), 684-690. doi:10.1016/j.jadohealth.2013.11.003

Marcoux, B. C., \& Shope, J. T. (1997). Application of the theory of planned behavior to adolescent use and misuse of alcohol. Health Education Research, 12(3), 323-331.

Marsee v. United States Tobacco Co., 639 F. Supp. 466 (W.D. Okla. 1986).

Marini, S., Buonanno, G., Stabile, L., \& Ficco, G. (2014). Short-term effects of electronic and tobacco cigarettes on exhaled nitric oxide. Toxicology and Applied Pharmacology, 278(1), 9-15.

McAuley, T. R., Hopke, P. K., Zhao, J., \& Babaian, S. (2012). Comparison of the effects of ecigarette vapor and cigarette smoke on indoor air quality. Inhalation toxicology, 24(12), 850-857.

McEachan, R. R. C., Conner, M., Taylor, N. J., Lawton, R. J., Robin, R., Mceachan, C., ... Jane, R. (2011). Prospective prediction of health-related behaviours with the Theory of Planned Behaviour: a meta-analysis. Health Psychology Review, 5, 97-144.

doi:10.1080/17437199.2010.521684

McGue, M., Elkins, I., \& Iacono, W. G. (2000). Genetic and environmental influences on adolescent substance use and abuse. American Journal of Medical Genetics, 96(5), 671677. doi:10.1002/1096-8628(20001009)96:5<671::AID-AJMG14>3.0.CO;2-W 
McKee, S. A., Maciejewski, P. K., Falba, T., \& Mazure, C. M. (2003). Sex differences in the effects of stressful life events on changes in smoking status. Addiction, 98(6), 847-855.

Measham, F., O’Brien, K., \& Turnbull, G. (2016). "Skittles \&amp; Red Bull is my favourite flavour": E-cigarettes, smoking, vaping and the changing landscape of nicotine consumption amongst British teenagers - implications for the normalisation debate. Drugs: Education, Prevention and Policy, 7637(September), 1-14.

http://doi.org/10.1080/09687637.2016.1178708

Mrug, S., Gaines, J., Su, W., \& Windle, M. (2010). School-level substance use: effects on early adolescents' alcohol, tobacco, and marijuana use. Journal of Studies on Alcohol and Drugs, 71(4), 488-95. http://doi.org/10.15288/jsad.2010.71.488

National Institutes of Health (2010 May 13). Propylene Gycol. Retrieved from http://toxnet.nlm.nih.gov/cgi-bin/sis/search/a?dbs+hsdb:@term+@DOCNO+174.

National Institutes of Health (2011 September 22). Glyerin. Retrieved from http://toxnet.nlm.nih.gov/cgi-bin/sis/search/a?dbs+hsdb:@term+@DOCNO+492

Office for Civil Rights Data Collection (2016). Wide-Ranging Education Access and Equity Data Collected from Our Nation's Public Schools. [Dataset]. Retrieved from http://ocrdata.ed.gov/

Orbell, S., Blair, C., Sherlock, K., \& Conner, M. (2001). The theory of planned behavior and ecstasy use: Roles for habit and perceived control over taking versus obtaining substances. Journal of Applied Social Psychology, 31(1), 31-47. 
Orellana-Barrios, M. A., Payne, D., Mulkey, Z., \& Nugent, K. (2015). Electronic cigarettes-a narrative review for clinicians. The American Journal of Medicine. doi:10.1016/j.amjmed.2015.01.033

Owusu, D., Aibangbee, J., Collins, C., Robertson, C., Wang, L., Littleton, M. A., ... \& Mamudu, H. M. (2016). The Use of E-cigarettes Among School-Going Adolescents in a Predominantly Rural Environment of Central Appalachia. Journal of Community Health, $1-8$.

Palamidas, A., Gennimata, S. A., Kaltsakas, G., Tsikrika, S., Vakali, S., Gratziou, C., \& Koulouris, N. (2013). Acute effect of an e-cigarette with and without nicotine on lung function. European Respiratory Journal, 42(Suppl 57), P1054.

Paschke, T., Sherer, G., \& Heller, W. D. (2002). Effects of ingredients on cigarette smoke composition and biological activity: A literature overview. Beiträge zur Tabakforschung / Contributions to Tobacco Research 20(3), 107-247.

Patrick, M. E., Miech, R. A., Carlier, C., O’Malley, P. M., Johnston, L. D., \& Schulenberg, J. E. (2016). Self-reported reasons for vaping among 8th, 10th, and 12th graders in the US: Nationally-representative results. Drug and Alcohol Dependence, 165, 275-278. http://doi.org/10.1016/j.drugalcdep.2016.05.017

Patten, C. A., Decker, P. A., Dornelas, E. A., Barbagallo, J., Rock, E., Offord, K. P., ... Pingree, S. (2008). Changes in readiness to quit and self-efficacy among adolescents receiving a brief office intervention for smoking cessation. Psychology, Health \& Medicine, 13(May), 326-336. doi:10.1080/13548500701426703 
Pearl, J. (2014). Comment: Understanding Simpson's Paradox. The American Statistician, 68(1), 8-13. https://doi.org/10.1080/00031305.2014.876829

Pentz, M. A., Shin, H., Riggs, N., Unger, J. B., Collison, K. L., \& Chou, C.-P. (2015). Parent, peer, and executive function relationships to early adolescent e-cigarette use: A substance use pathway? Addictive Behaviors, 42, 73-78. doi:10.1016/j.addbeh.2014.10.040

Pepper, J. K., \& Brewer, N. T. (2013). Electronic nicotine delivery system (electronic cigarette) awareness, use, reactions and beliefs: a systematic review. Tobacco Control, 1-10. http://doi.org/10.1136/tobaccocontrol-2013-051122

Pepper, J. K., Emery, S. L., Ribisl, K. M., Rini, C. M., \& Brewer, N. T. (2015). How risky is it to use e-cigarettes? Smokers' beliefs about their health risks from using novel and traditional tobacco products. Journal of Behavioral Medicine, 38(2), 318-326. http://doi.org/10.1007/s10865-014-9605-2

Pepper, J. K., Reiter, P. L., McRee, A. L., Cameron, L. D., Gilkey, M. B., \& Brewer, N. T. (2013). Adolescent males' awareness of and willingness to try electronic cigarettes. Journal of Adolescent Health, 52(2), 144-150. doi:10.1016/j.jadohealth.2012.09.014

Perkins, H. W. (2002). Social norms and the prevention of alcohol misuse in collegiate contexts. Journal of Studies on Alcohol. Supplement, (14), 164-172.

Peters, R. J., Meshack, A., Lin, M.-T., Hill, M., \& Abughosh, S. (2013). The social norms and beliefs of teenage male electronic cigarette use. Journal of Ethnicity in Substance Abuse, 12(4), 300-7. doi:10.1080/15332640.2013.819310 
Petraitis, J., Flay, B. R., \& Miller, T. Q. (1995). Reviewing theories of adolescent substance use: organizing pieces in the puzzle. Psychological Bulletin, 117(1), 67-86. doi:10.1037/0033-2909.117.1.67

Pirie, P. L., Murray, D. M., \& Luepker, R. V. (1991). Gender differences in cigarette smoking and quitting in a cohort of young adults. American Journal of Public Health, 81(3), 324327. doi:10.2105/AJPH.81.3.324

Pisinger, C., \& Døssing, M. (2014). A systematic review of health effects of electronic cigarettes. Preventive Medicine, 69, 248-260. doi:10.1016/j.ypmed.2014.10.009

Rait, M. A., Prochaska, J. J., \& Rubinstein, M. L. (2015). Recruitment of adolescents for a smoking study: use of traditional strategies and social media. Translational Behavioral Medicine, 5(3), 254-259. http://doi.org/10.1007/s13142-015-0312-5

Ramirez, R., Hinman, A., Sterling, S., Weisner, C., \& Campbell, C. (2012). Peer Influences on Adolescent Alcohol and Other Drug Use Outcomes. Journal of Nursing Scholarship, 44(1), 36-44. doi:Doi 10.1111/J.1547-5069.2011.01437.X

Ramo, D. E., Young-Wolff, K. C., \& Prochaska, J. J. (2015). Prevalence and correlates of electronic-cigarette use in young adults: Findings from three studies over five years. Addictive Behaviors, 41, 142-147. doi:10.1016/j.addbeh.2014.10.019

Roditis, M. L., \& Halpern-Felsher, B. (2015). Adolescents' Perceptions of Risks and Benefits of Conventional Cigarettes, E-cigarettes, and Marijuana: A Qualitative Analysis. Journal of Adolescent Health, 57(2), 179-185. http://doi.org/10.1016/j.jadohealth.2015.04.002 
Romagna, G., Allifranchini, E., Bocchietto, E., Todeschi, S., Esposito, M., \& Farsalinos, K. E. (2013). Cytotoxicity evaluation of electronic cigarette vapor extract on cultured mammalian fibroblasts (ClearStream-LIFE): comparison with tobacco cigarette smoke extract. Inhalation Toxicology, 25(6), 354-361.

Scheier, L. M., Botvin, G. J., \& Miller, N. L. (2000). Life events, neighborhood stress, psychosocial functioning, and alcohol use among urban minority youth. Journal of Child \& Adolescent Substance Abuse, 9(1), 19-50. doi:10.1300/J029v09n01_02

Schober, W., Szendrei, K., Matzen, W., Osiander-Fuchs, H., Heitmann, D., Schettgen, T., ... Fromme, H. (2014). Use of electronic cigarettes (e-cigarettes) impairs indoor air quality and increases FeNO levels of e-cigarette consumers. International Journal of Hygiene and Environmental Health, 217(6), 628-637. http://doi.org/10.1016/j.ijheh.2013.11.003

Shrier, L. A., Harris, S. K., Sternberg, M., \& Beardslee, W. R. (2001). Associations of depression, self-esteem, and substance use with sexual risk among adolescents. Preventive Medicine, 33(3), 179-189.

Simons-Morton, B. G., \& Farhat, T. (2010). Recent findings on peer group influences on adolescent smoking. The Journal of Primary Prevention, 31(4), 191-208.

Stacy, A. W., Newcomb, M. D., \& Bentler, P. M. (1991). Cognitive motivation and drug use: a 9-year longitudinal study. Journal of Abnormal Psychology, 100(4), 502.

Stein, J. A., Newcomb, M. D., \& Bentler, P. M. (1987). An 8-year study of multiple influences on drug use and drug use consequences. Journal of Personality and Social Psychology, 53(6), 1094. 
Stephenson, M. T., Hoyle, R. H., Palmgreen, P., \& Slater, M. D. (2003). Brief measures of sensation seeking for screening and large-scale surveys. Drug and Alcohol Dependence, 72, 279-286. https://doi.org/10.1016/j.drugalcdep.2003.08.003

Sutfin, E. L., McCoy, T. P., Morrell, H. E. R., Hoeppner, B. B., \& Wolfson, M. (2013). Electronic cigarette use by college students. Drug and Alcohol Dependence, 131(3), 214221. doi:10.1016/j.drugalcdep.2013.05.001

Tavolacci, M.-P., Vasiliu, A., Romo, L., Kotbagi, G., Kern, L., \& Ladner, J. (2016). Patterns of electronic cigarette use in current and ever users among college students in France: a crosssectional study. BMJ Open, 6(5), e011344. http://doi.org/10.1136/bmjopen-2016-011344

Tyas, S., \& Pederson, L. (1998). Psychosocial factors related to adolescent smoking: a critical review of the literature. Tobacco Control, 7, 409-420.

Vaporfi (2015). Vaporfi E-Liquids. Retrieved from http://www.vaporfi.com/e-liquid-cartridges/

Vardavas, C. I., Anagnostopoulos, N., Kougias, M., Evangelopoulou, V., Connolly, G. N., \& Behrakis, P. K. (2012). Short-term pulmonary effects of using an electronic cigarette: Impact on respiratory flow resistance, impedance, and exhaled nitric oxide. Chest, 141, 1400-1406. doi:10.1378/chest.11-2443

Westenberger, B. J. (2009). Evaluation of e-cigarettes. Retrieved from www.fda.gov/downloads/Drugs/ScienceResearch/UCM173250.pdf

Williams, R. J., \& Knight, R. (2015). Insights in Public Health Electronic Cigarettes: Marketing to Hawai'i's Adolescents. Hawai'i Journal of Medicine \& Public Health, 74(2), 66. 
Williams, M., Villarreal, A., Bozhilov, K., Lin, S., \& Talbot, P. (2013). Metal and silicate particles including nanoparticles are present in electronic cigarette cartomizer fluid and aerosol. PloS One, 8(3), e57987.

Wills, T. A., Knight, R., Sargent, J. D., Gibbons, F. X., Pagano, I., \& Williams, R. J. (2016). Longitudinal study of e-cigarette use and onset of cigarette smoking among high school students in Hawaii. Tobacco Control, 26(1), 34-39. http://doi.org/10.1136/tobaccocontrol2015-052705

Wills, T. A., Knight, R., Williams, R. J., Pagano, I., \& Sargent, J. D. (2015). Risk factors for exclusive e-cigarette use and dual e-cigarette use and tobacco use in adolescents. Pediatrics, 135(1), e43-e51. doi:10.1542/peds.2014-0760

Wills, T. A., Sandy, J. M., Shinar, O., \& Yaeger, A. (1999). Contributions of positive and negative affect to adolescent substance use: Test of a bidimensional model in a longitudinal study. Psychology of Addictive Behaviors, 13(4), 327-338. doi:10.1037/0893-164X.13.4.327

World Health Organization (2011). WHO report on the global tobacco epidemic. 1-150.

Yamin, C. K., Bitton, A., \& Bates, D. W. (2010). E-Cigarettes: A rapidly growing internet phenomenon. Annals of Internal Medicine, 153(9), 607-610 
Table 1

Coding of Predictor Variables Used in Analyses

\begin{tabular}{|c|c|c|}
\hline Variable & Coding & $\begin{array}{r}\text { Measure } \\
\text { Taken From }\end{array}$ \\
\hline $\begin{array}{l}\text { Immediate Family History of Substance } \\
\text { Dependence }\end{array}$ & $\begin{array}{r}0=\text { No history } \\
1=\text { Family history of dependence }\end{array}$ & SIF \\
\hline $\begin{array}{l}\text { Extended Family History of Substance } \\
\text { Dependence }\end{array}$ & $\begin{array}{l}0=\text { No history } \\
1=\text { Family history of dependence }\end{array}$ & SIF \\
\hline Gender & $\begin{array}{l}1=\text { Male } \\
2=\text { Female }\end{array}$ & SIF \\
\hline Intact Family & $\begin{array}{r}0=\text { Not intact } \\
1=\text { Intact }\end{array}$ & SIF \\
\hline Population Density & $\begin{array}{r}\text { Higher Values }=\text { More people per square } \\
\text { mile }\end{array}$ & SIF \\
\hline $\begin{array}{l}\text { Percent of Students Receiving Free } \\
\text { School Lunches (SES) }\end{array}$ & Higher values $=$ More students receiving & SIF \\
\hline Grades & Higher values $=$ Lower grades & SIF \\
\hline Alcohol Use & $\begin{array}{r}0=\text { Never tried alcohol } \\
1=\text { Have at least one drink of alcohol }\end{array}$ & YRBS \\
\hline Cigarette use & $\begin{array}{l}0=\text { Never tried a cigarette } \\
1=\text { Tried a cigarette at least once }\end{array}$ & YRBS \\
\hline Marijuana Use & $\begin{array}{r}\text { Higher values }=\text { More frequent marijuana } \\
\text { use/earlier age of marijuana use }\end{array}$ & YRBS \\
\hline Modeling of Smoking & $\begin{array}{r}\text { Higher values }=\text { More cigarette and e-cig } \\
\text { use by peers/parents }\end{array}$ & YRBS \\
\hline Exposure to Advertising about E-Cigs & $\begin{array}{l}\text { Higher Values = Exposure to more } \\
\text { sources of advertising (Range }=0-11)\end{array}$ & YRBS \\
\hline Extraversion & $\begin{array}{r}\text { Higher values }=\text { High self-rating of } \\
\text { extraversion }(\text { Range }=1-7)\end{array}$ & MINI-IPIP \\
\hline Benefits of E-Cig use & $\begin{array}{r}\text { Higher values }=\text { More perceived benefits } \\
\text { of using an e-cig (Range }=0-9)\end{array}$ & SESA \\
\hline Costs of E-Cig use & $\begin{array}{r}\text { Higher values }=\text { More perceived costs of } \\
\text { using an e-cig (Range }=0-9)\end{array}$ & SESA \\
\hline Self-Efficacy to Resist E-Cigs & $\begin{array}{l}\text { Higher values = Greater self-efficacy to } \\
\text { resist using an e-cig (Range = 1-6) }\end{array}$ & SSES \\
\hline Sensation-Seeking & $\begin{array}{r}\text { Higher values }=\text { More sensation seeking } \\
(\text { Range }=1-5)\end{array}$ & BSSS \\
\hline
\end{tabular}


Table 2

Participant Demographics

\begin{tabular}{llc}
\hline Variables $(N=493)$ & & $\mathrm{M}(\mathrm{SD}) / \mathrm{n}(\%)$ \\
\hline Age & & $15.99(1.20)$ \\
Gender & Female & \\
Race & Caucasian & $285(57.9 \%)$ \\
& African-Am. & \\
& Asian-Am. & $408(83.8 \%)$ \\
& Bi-Racial/Mixed Race & $16(3.3 \%)$ \\
& Hispanic American & $23(4.7 \%)$ \\
& Other & $28(5.7 \%)$ \\
& & $8(1.6 \%)$ \\
Grade in School & Freshman & $4(0.8 \%)$ \\
& Sophomore & $63(12.8 \%)$ \\
& Junior & $173(35.2 \%)$ \\
& Senior & $145(29.5 \%)$ \\
& & $111(22.6 \%)$ \\
& Intact & $304(62.9 \%)$ \\
& Blended & $79(16.4 \%)$ \\
& Single/Separated & $100(20.7 \%)$ \\
\hline
\end{tabular}


Table 3

Frequencies

\begin{tabular}{llc}
\hline Variables $(N=493)$ & & $\mathrm{n}(\%)$ \\
\hline $\begin{array}{l}\text { Substance Dependence } \\
\text { in Immediate Family? }\end{array}$ & Yes & $86(17.4 \%)$ \\
$\begin{array}{l}\text { Substance Dependence } \\
\text { in Extended Family? }\end{array}$ & Yes & \\
& & $229(46.5 \%)$ \\
Grades & Mostly A's & \\
& A/B's & $186(37.7 \%)$ \\
& All or Mostly B's & $203(41.2 \%)$ \\
& B/C's & $30(6.1 \%)$ \\
& All or Mostly C's & $56(11.4 \%)$ \\
& C/D's & $10(2.0 \%)$ \\
& All or Mostly D's & $5(1.0 \%)$ \\
& D/F's & $2(0.4 \%)$ \\
& & $1(0.2 \%)$ \\
Ever Used a Cigarette? & Yes & $122(24.7 \%)$ \\
& & $275(55.8 \%)$ \\
\hline
\end{tabular}


Table 4

Descriptive Statistics

\begin{tabular}{|c|c|c|c|c|}
\hline & Mean/N(\%) & SD & Min & Max \\
\hline $\begin{array}{l}\text { Percent of Students Receiving Free School } \\
\text { Lunches (SES) }\end{array}$ & 24.85 & 14.16 & 4.6 & 47.3 \\
\hline $\begin{array}{l}\text { Population Density }{ }^{\mathrm{a}} \text { (people per square } \\
\text { mile) }\end{array}$ & 426.48 & 220.53 & 50 & 744 \\
\hline Exposure to E-Cig Advertising ${ }^{\mathrm{b}}$ & 3.24 & 1.80 & 0 & 10 \\
\hline Marijuana Use ${ }^{c}$ & .01 & 1.76 & --.85 & 8.31 \\
\hline Modeling of Smoking ${ }^{\mathrm{d}}$ & -.03 & 3.48 & -3.16 & 12.89 \\
\hline Sensation Seeking ${ }^{\mathrm{e}}$ & 3.11 & .68 & 1.25 & 47.75 \\
\hline Extraversion $^{\mathrm{e}}$ & 3.15 & .99 & 1 & 5 \\
\hline Agreeableness ${ }^{\mathrm{e}}$ & 3.76 & .80 & 1 & 5 \\
\hline Conscientiousness $^{\mathrm{e}}$ & 3.42 & .80 & 1 & 5 \\
\hline Neuroticism $^{\mathrm{e}}$ & 2.91 & .74 & 1 & 5 \\
\hline Intellect/Imagination $^{\mathrm{e}}$ & 3.70 & .66 & 2 & 5 \\
\hline Benefits of E-Cig Use ${ }^{f}$ & 2.22 & 1.71 & 0 & 7.69 \\
\hline Costs of E-Cig Use ${ }^{f}$ & 4.58 & 2.62 & 0 & 9 \\
\hline Self-Efficacy to Resist Using an E-Cig ${ }^{\mathrm{g}}$ & 5.25 & 1.03 & 1 & 7.67 \\
\hline
\end{tabular}

${ }^{a}$ Population Density based on zip code for residence provided by participants

${ }^{b}$ Higher values indicate exposure to more unique sources of advertising about e-cigs

${ }^{c}$ Higher values indicate more frequent marijuana use and earlier age of first marijuana use

${ }^{\mathrm{d}}$ Higher values indicate more cigarette and e-cigarette use among peers and parents

${ }^{e}$ Higher values represent greater reports of the respective trait

${ }^{f}$ Higher values indicate more perceived benefits or costs of using an e-cig

${ }^{g}$ Higher values mean teens feel that they would be more likely to resist using an e-cig if offered 
Table 5

Binomial Logistic Regression Classification Table

\begin{tabular}{lccc}
\hline & \multicolumn{3}{c}{ Predicted } \\
\cline { 2 - 4 } Observed & $\begin{array}{c}\text { Have not used E- } \\
\text { Cig }\end{array}$ & Used E-Cig & $\%$ Correct \\
\hline $\begin{array}{l}\text { Have not used E- } \\
\text { Cig }\end{array}$ & 285 & 22 & $92.8 \%$ \\
Used E-Cig & 24 & 162 & $87.1 \%$ \\
Overall \% & & & $90.7 \%$ \\
\hline
\end{tabular}


Table 6

Binomial Logistic Regression Predicting Lifetime Electronic Cigarette Use

\begin{tabular}{lcccc}
\hline & Wald & p-value & SE & OR (95\% CI) \\
\hline Family History of Substance use & & & & \\
SES $^{\mathrm{a}}$ & 2.02 & .16 & .50 & $.49(.19-1.31)$ \\
Conventional Cigarette Use $^{\mathrm{b}}$ & 1.40 & .24 & .19 & $1.25(.87-1.84)$ \\
Alcohol Use $^{\mathrm{b}}$ & 5.30 & .02 & .46 & $2.86(1.16-6.97)$ \\
Marijuana Use $^{\mathrm{b}}$ & 6.81 & .01 & .38 & $2.67(1.27-5.57$ \\
Modeling of Smoking $^{\mathrm{b}}$ & 14.23 & $<.001$ & .21 & $2.23(1.47-3.42)$ \\
Perceived Costs $^{\mathrm{c}}$ & 20.58 & $<.001$ & .06 & $1.34(1.18-1.52)$ \\
Perceived Benefits $^{\mathrm{c}}$ & 10.93 & .001 & .20 & $.52(.36-.78)$ \\
Self-Efficacy to Resist E-Cigs $^{\mathrm{d}}$ & & & & \\
Sensation Seeking $^{\mathrm{e}}$ & 2.77 & .10 & .20 & $1.39(.92-2.02$ \\
Extraversion $^{\mathrm{f}}$ & 25.84 & $<.001$ & .30 & $.22(.15-.42)$ \\
\hline
\end{tabular}

Note: No lifetime use is the referent category

Variables obtained from:

${ }^{\mathrm{a}} \mathrm{SIF}$

${ }^{\mathrm{b}}$ YRBS

'SESA

${ }^{\mathrm{d}} \mathrm{SSES}$

${ }^{\mathrm{e} B S S S}$

${ }^{\mathrm{f}}$ MINI-IPIP 
Table 7

Multinomial Logistic Regression Classifying Level of E-Cig Use

\begin{tabular}{lcccc}
\hline & \multicolumn{4}{c}{ Predicted } \\
\cline { 2 - 5 } Observed & Never & Lifetime-Only & Past 30 Day & \% Correct \\
\hline Never & 288 & 14 & 5 & $93.8 \%$ \\
Lifetime-Only & 26 & 50 & 21 & $51.5 \%$ \\
Past 30 Day & 5 & 34 & 54 & $60.7 \%$ \\
Overall \% & $64.7 \%$ & $19.1 \%$ & $16.2 \%$ & $79.5 \%$ \\
\hline
\end{tabular}


Table 8

Multinomial Logistic Regression Predicting Levels of E-Cig Use

Never vs. Lifetime Only

Lifetime vs. Past 30 Day Use

Wald (SE) P-value OR $(95 \% \mathrm{CI}) \quad$ Wald (SE) P-value $\quad$ OR $(95 \% \mathrm{CI})$

\begin{tabular}{|c|c|c|c|c|c|c|}
\hline Family History of Substance use & $1.4(.51)$ & .24 & $.55(.20-1.49)$ & $.63(.42)$ & .43 & $1.40(.61-3.21)$ \\
\hline Cig Use & $5.56(.47)$ & .02 & $.30(.13-.81)$ & $.17(.41)$ & .68 & $1.18(.53-2.63)$ \\
\hline Alcohol Use & $6.59(.40)$ & .01 & $.36(.17-.79)$ & $.05(.47)$ & .83 & $.90(.44-2.80)$ \\
\hline Marijuana Use & $9.92(.22)$ & .002 & $.50(.32-.77)$ & $4.47(.17)$ & .04 & $1.44(1.03-2.02)$ \\
\hline SES & $1.71(.20)$ & .19 & $.77(.53-1.14)$ & $.23(.20)$ & .63 & $.91(.62-1.34)$ \\
\hline Modeling of Smoking & $16.46(.07)$ & $<.001$ & $.77(.67-.87)$ & $2.60(.06)$ & .11 & $1.10(.98-1.22)$ \\
\hline Perceived Costs & $7.21(.20)$ & .01 & $1.73(1.16-2.57)$ & $5.13(.23)$ & .02 & $.59(.37-.93)$ \\
\hline Perceived Benefits & $2.70(.21)$ & .10 & $.71(.48-1.07)$ & $.01(.19)$ & .92 & $1.02(.70-1.48)$ \\
\hline Self-Efficacy to Resist E-Cigs & $18.59(.31)$ & $<.001$ & $3.74(2.05-6.81)$ & $12.40(.19)$ & $<.001$ & $.51(.35-.74)$ \\
\hline Sensation Seeking & $2.15(.21)$ & .14 & $1.37(.90-2.07)$ & $1.62(.21)$ & .20 & $1.30(.87-1.96)$ \\
\hline Extraversion & $15.07(.22)$ & $<.001$ & $.44(.29-.66)$ & $.68(.19)$ & .41 & $.86(.59-1.24)$ \\
\hline
\end{tabular}




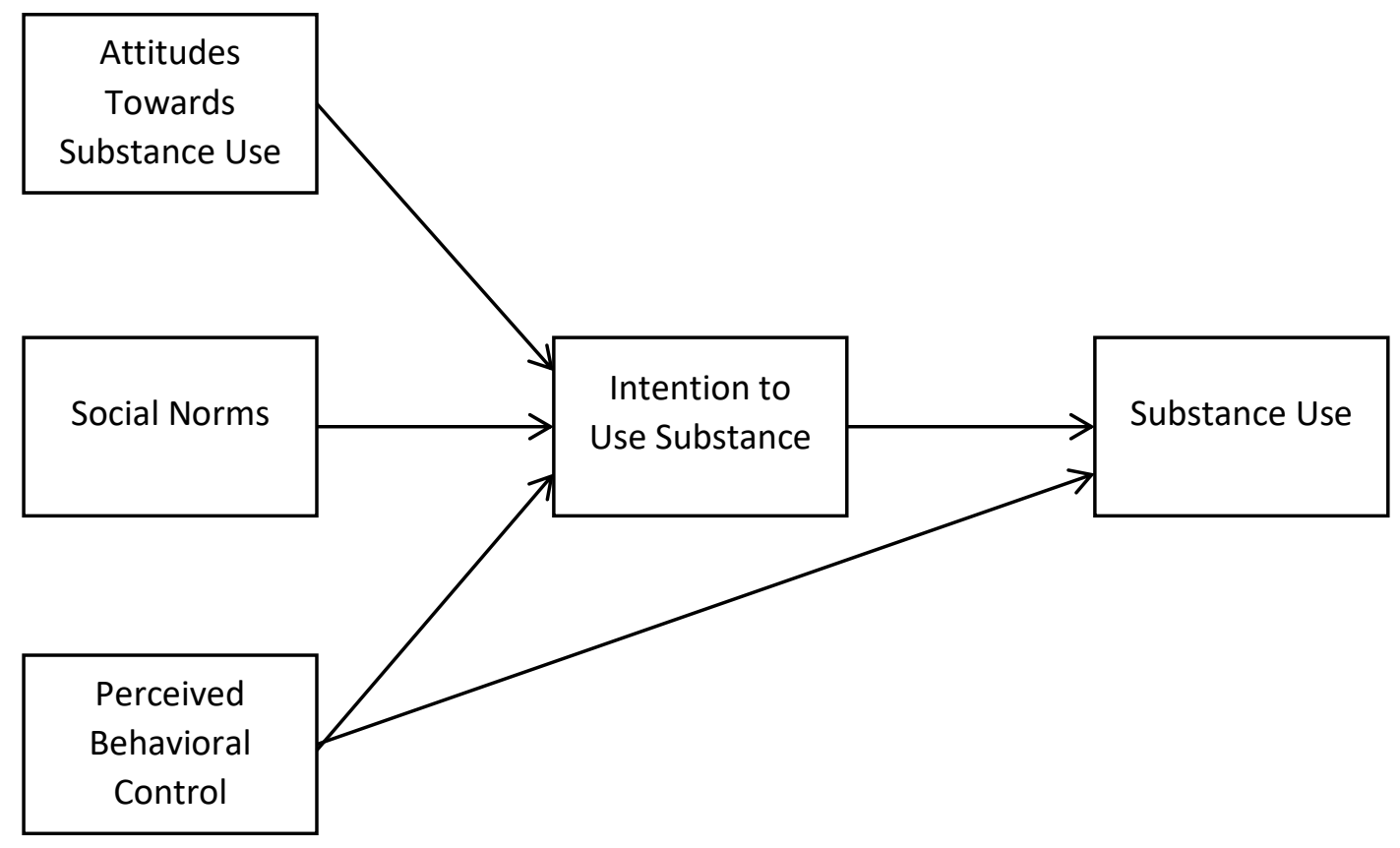

Figure 1. Theory of Planned Behavior. This figure displays the theoretical model for the Theory of Planned Behavior. 

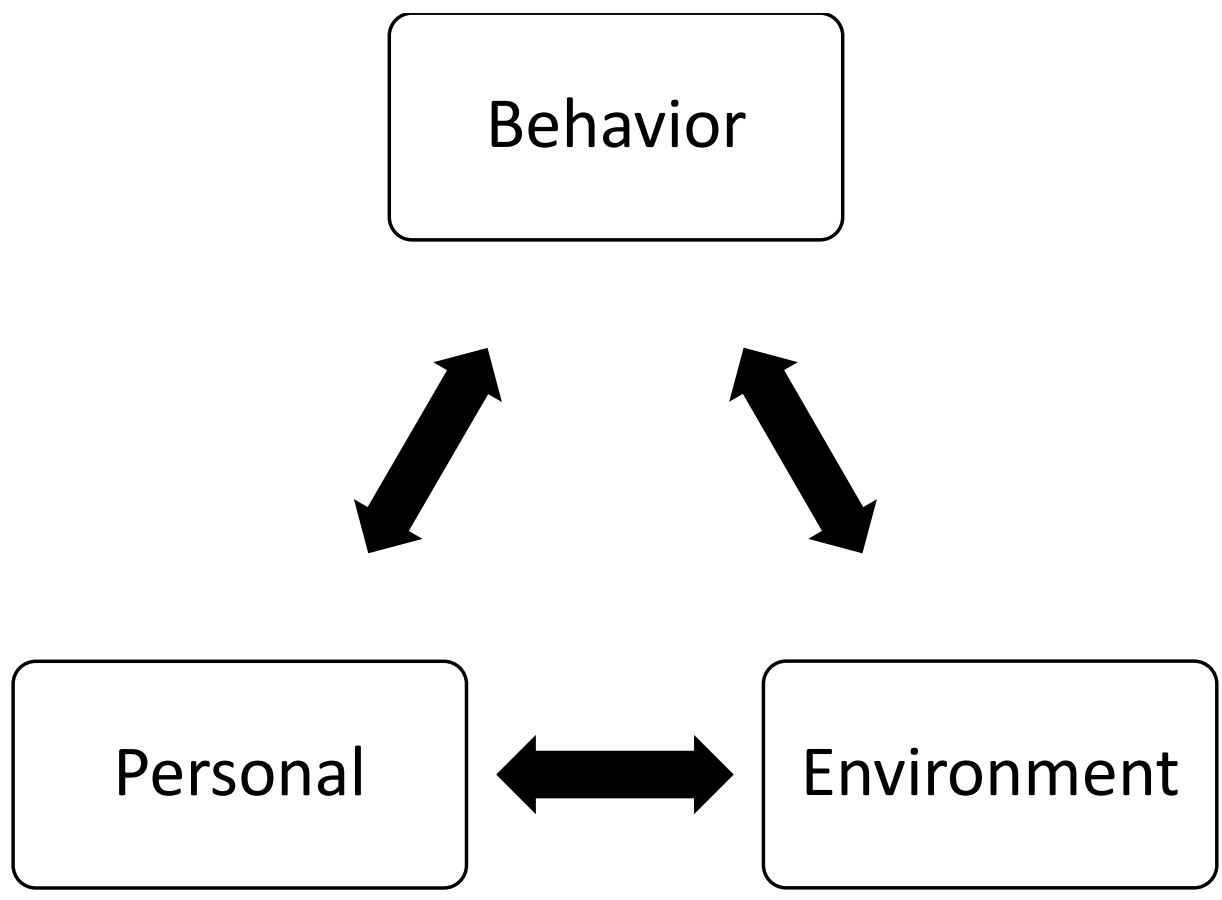

Figure 2. Social Cognitive Theory. This figure shows the theoretical framework for social cognitive theory. 


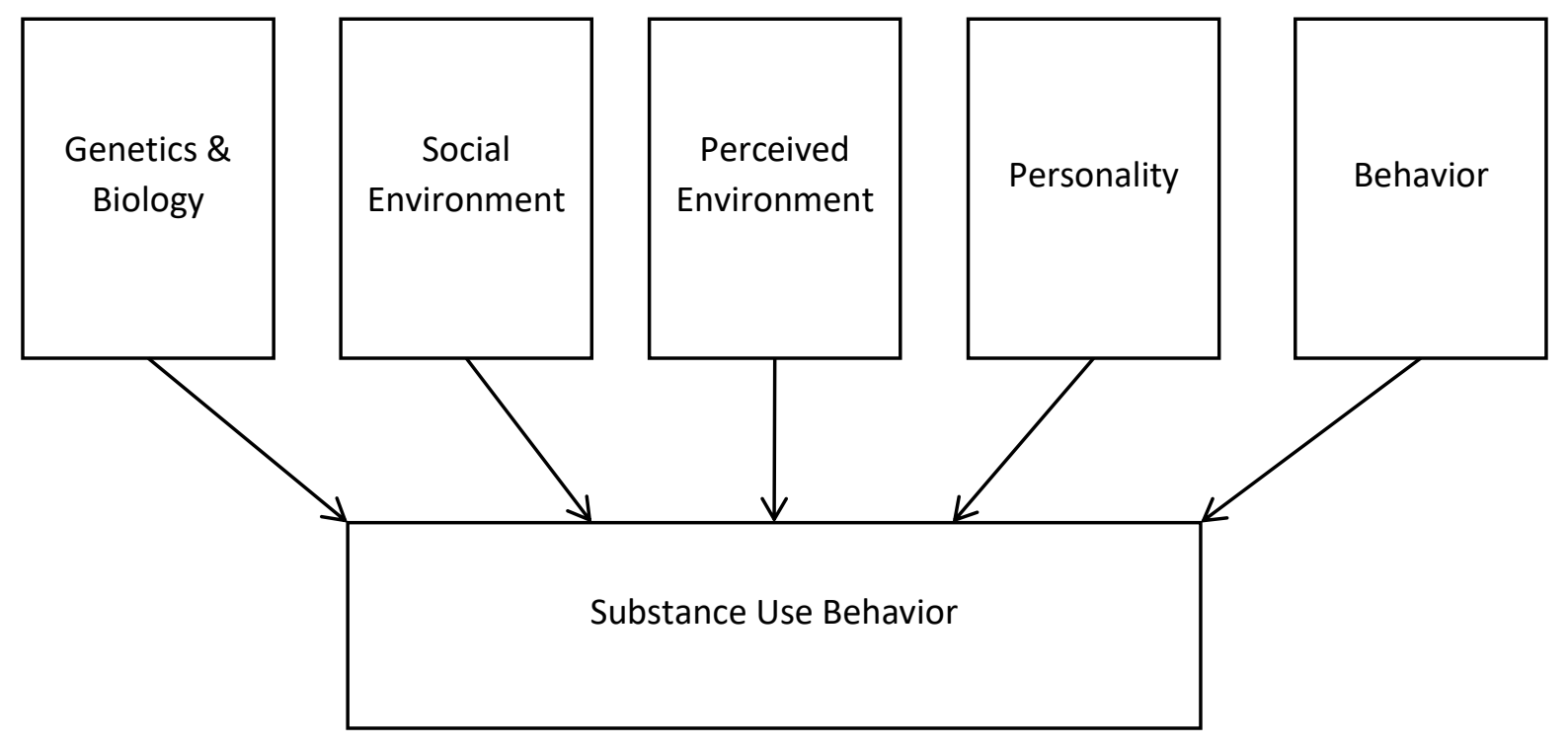

Figure 3. Conceptual Framework for Problem Behavior Theory. Adapted from "Risk behavior in adolescence: A psychosocial framework for understanding and action,” by R. Jessor, 2001, Journal of Adolescent Health, 12, 597-605. 


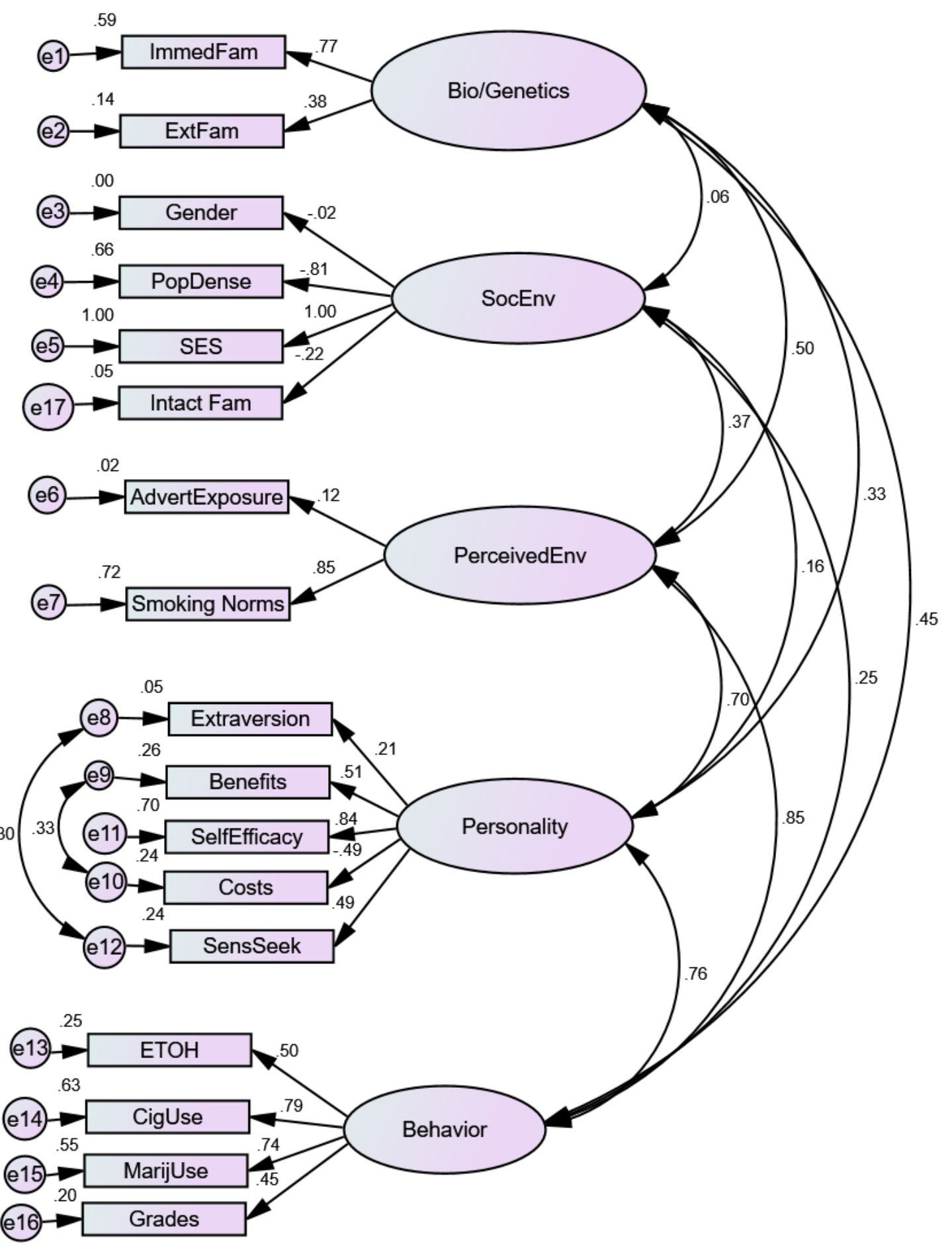

Figure 4: First Iteration of Measurement Model. This figure displays the loadings of the observed variables onto the latent constructs of PBT in the first iteration of the measurement model. Note: Immed/ExtFam = Substance dependence in immediate or extended family; PopDense =Population Density; AdvertExposure = Exposure to E-Cig Advertisements; ETOH = Alcohol Use; MarijUse = Marijuana Use. 


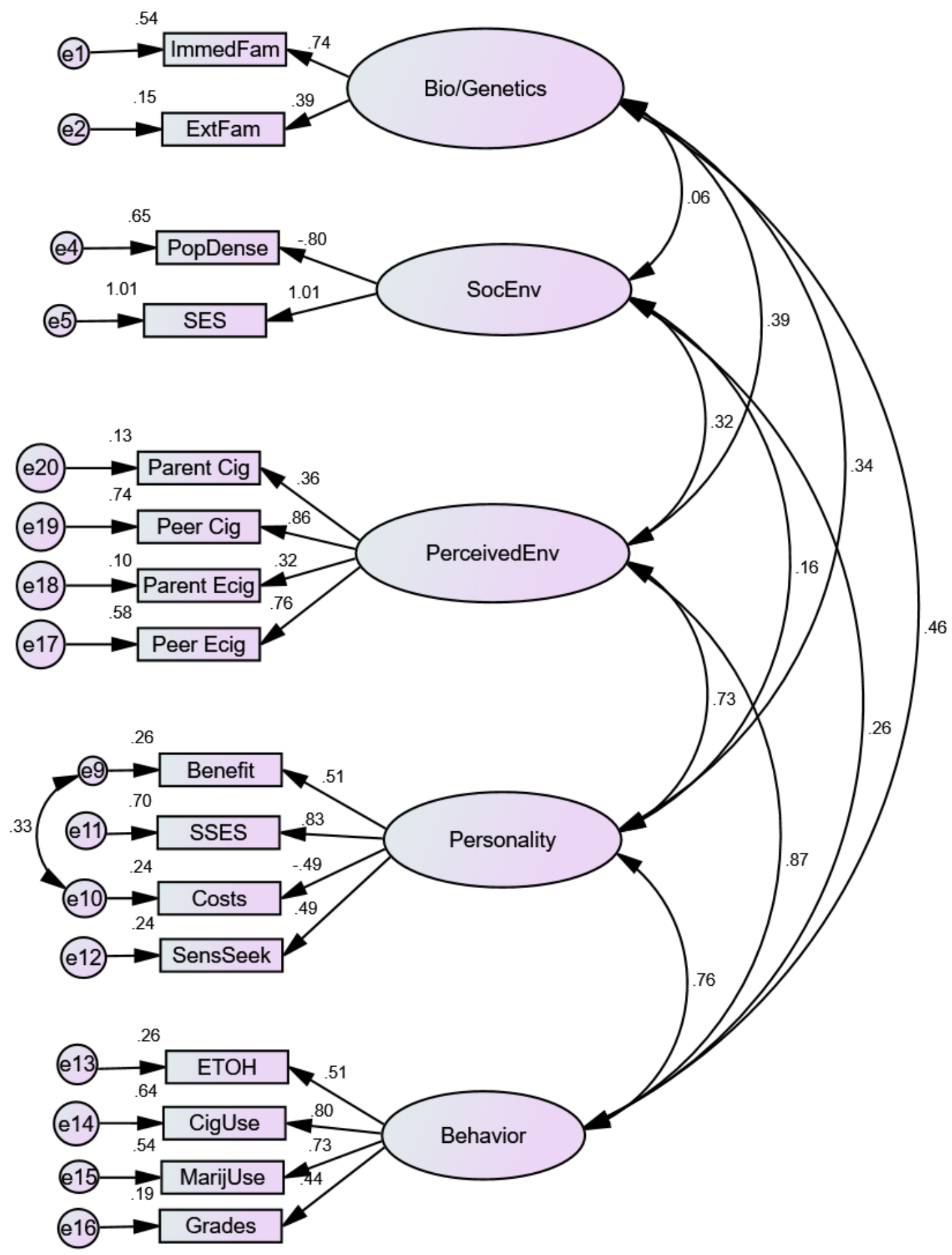

Figure 5. Second Iteration of Measurement Model. This figure displays the loadings of the observed variables onto the latent constructs of PBT in the second iteration of the measurement model. Note: Immed/ExtFam = Substance dependence in immediate or extended family; PopDense =Population Density; ETOH = Alcohol Use; MarijUse = Marijuana Use . 


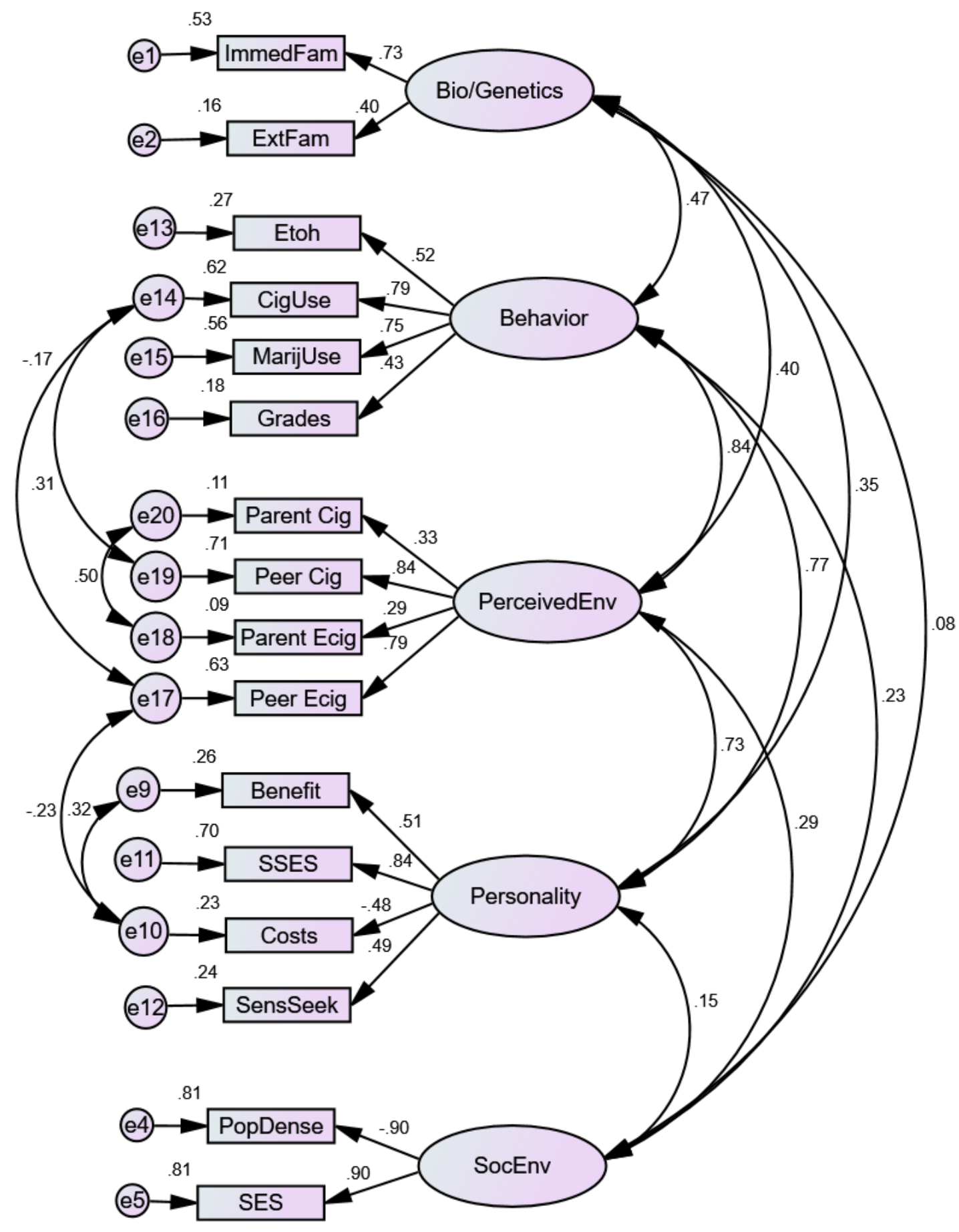

Figure 6. Third and Final Iteration of Measurement Model. This figure displays the loadings of the observed variables onto the latent constructs of PBT in the third iteration of the measurement model. Note: Immed/ExtFam = Substance dependence in immediate or extended family; PopDense =Population Density; ETOH = Alcohol Use; MarijUse = Marijuana Use . 


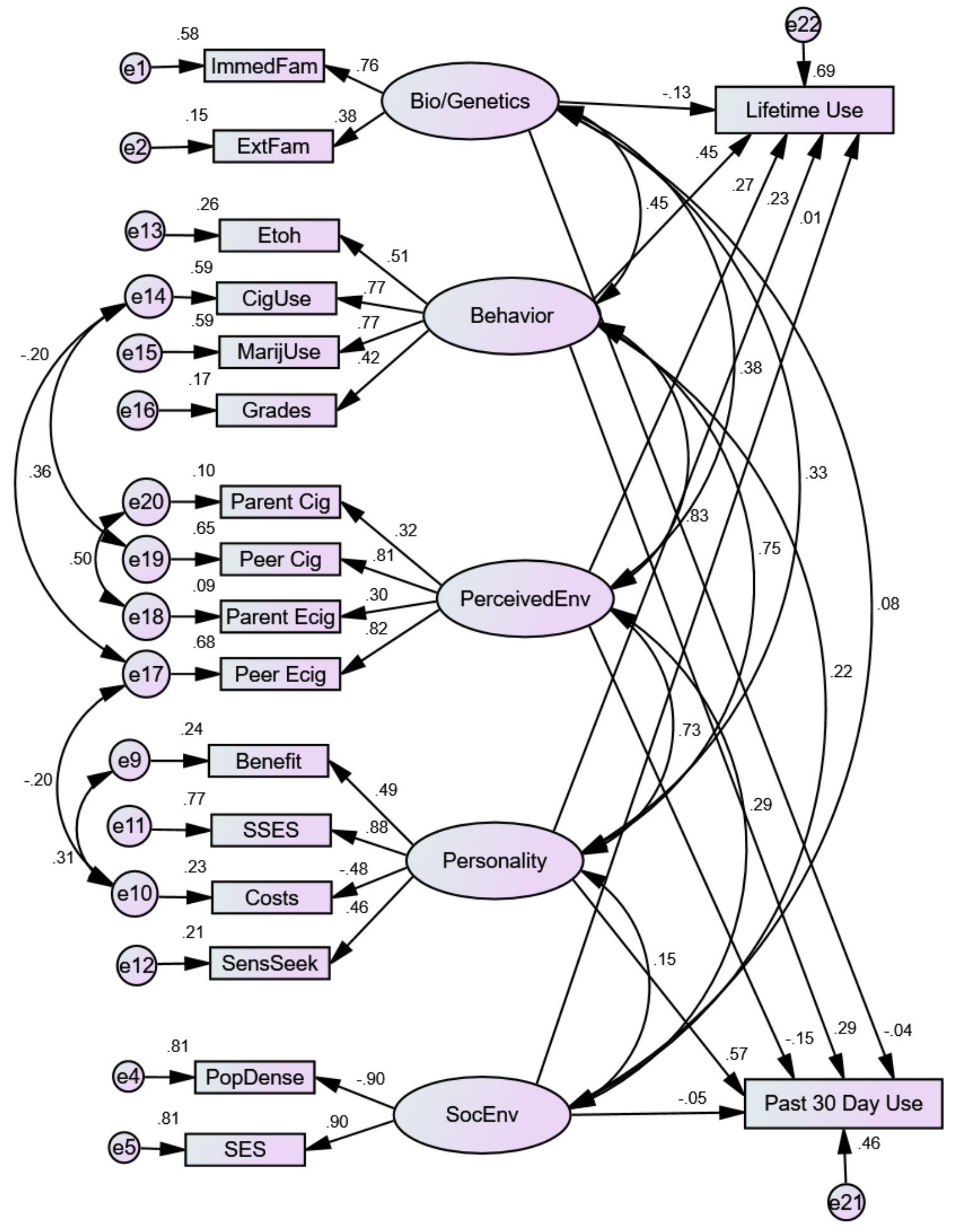

Figure 7. Structural Model of PBT. This figure shows latent variables predicting lifetime and current (past-30-day) use of electronic cigarettes. Note: Immed/ExtFam = Substance dependence in immediate or extended family; PopDense =Population Density; ETOH = Alcohol Use; MarijUse = Marijuana Use. 